\title{
Impact of the Ocean Mixed Layer Diurnal Variations on the Intraseasonal Variability of Sea Surface Temperatures in the Atlantic Ocean*
}

\author{
VIRGINIE GUEMAS \\ Centre National de Recherches Météorologiques/Groupe d'Etude de l'Atmosphère Météorologique, Météo-France, \\ CNRS, Toulouse, and Laboratoire des Sciences du Climat et de l'Environnement/IPSL, UMR 8212, \\ CEA-CNRS-UVSQ, Gif-sur-Yvette, France \\ DAVID SALAS-MÉLIA \\ Centre National de Recherches Météorologiques/Groupe d'Etude de l'Atmosphère Météorologique, Météo-France, \\ CNRS, Toulouse, France \\ MASA KAGEYAMA \\ Laboratoire des Sciences du Climat et de l'Environnement/IPSL, UMR 8212, CEA-CNRS-UVSQ, Gif-sur-Yvette, France \\ Hervé Giordani ANd Aurore Voldoire \\ Centre National de Recherches Météorologiques/Groupe d'Etude de l'Atmosphère Météorologique, Météo-France, \\ CNRS, Toulouse, France
}

(Manuscript received 4 February 2010, in final form 13 December 2010)

\begin{abstract}
This study investigates the nonlinear processes by which the ocean diurnal variations can affect the intraseasonal sea surface temperature (SST) variability in the Atlantic Ocean. The Centre National de Recherches Météorologiques one-dimensional ocean model (CNRMOM1D) is forced with the 40-yr ECMWF Re-Analysis (ERA-40) surface fluxes with a 1-h frequency in solar heat flux in a first simulation and with a daily forcing frequency in a second simulation. This model has a vertical resolution of $1 \mathrm{~m}$ near the surface. The comparison between both experiments shows that the daily mean surface temperature is modified by about $0.3^{\circ}-0.5^{\circ} \mathrm{C}$ if the ocean diurnal variations are represented, and this correction can persist for 15-40 days in the midlatitudes and more than 60 days in the tropics. The so-called rectification mechanism, by which the ocean diurnal warming enhances the intraseasonal SST variability by $20 \%-40 \%$, is found to be robust in the tropics. In contrast, in the midlatitudes, diurnal variations in wind stress and nonsolar heat flux are shown to affect the daily mean SST. For example, an intense wind stress or nonsolar heat flux toward the atmosphere during the first half of the day followed by weak fluxes during the second half result in a shallow mixed layer. The following day, the preconditioning results in heat being trapped near the surface and the daily mean surface temperature being higher than if these diurnal variations in surface forcings were not resolved.
\end{abstract}

* Supplemental information related to this paper is available at the Journals Online Web site: http://dx.doi.org/10.1175/2010JCLI3660.s1.

Corresponding author address: Virginie Guemas, IC3-Institut Català de Ciències del Clima, Carrer del Doctor Trueta, 203, 08005 Barcelona, Spain.

E-mail: vguemas@ic3.cat

\section{Introduction}

a. Ocean potential role in the atmospheric variability

To a first-order approximation, the ocean is driven by the atmosphere in the midlatitudes (Bjerknes 1964) while both are strongly coupled in the tropics as shown by the mechanisms leading to the El Niño-Southern 
Oscillation (ENSO) and Madden-Julian oscillation (MJO). However, both in the midlatitudes and in the tropics, sea surface temperature (SST) variations influence the heat exchanges between the atmosphere and the ocean. On average, the SST differs from the mixed layer temperature by about $0.1^{\circ} \mathrm{C}$ (Grodsky et al. 2008), and thus SST is related to the heat content of the ocean mixed layer. As a large potential source of heat and moisture, the ocean mixed layer can influence the atmospheric modes of variability. Previous studies emphasized the role of the surface ocean on the atmospheric circulation variability in the North Atlantic European region on daily (Guemas et al. 2010, 2009) to seasonal time scales (Czaja and Frankignoul 1999, 2002; Terray and Cassou 2002; Drévillon et al. 2001, 2003; Cassou et al. 2004a,b). For instance, the North Atlantic Oscillation (NAO) (Hurrell et al. 2003), which constitutes the main mode of variability in the North Atlantic European region, responds to SST anomalies in the tropical North Atlantic Ocean (Terray and Cassou 2002; Drévillon et al. 2003; Cassou et al. 2004b) via an enhancement of the Hadley cell and a propagation of the stationary-wave activity from the subtropics into the mid- to high latitudes (Terray and Cassou 2002). On a time scale of a few days, the North Atlantic Ocean produces a weak negative feedback on the negative phase of the North Atlantic Oscillation (Guemas et al. 2010). These examples highlight the role of the surface ocean in modulating the atmospheric state.

The impact of SST variations on the atmospheric modes of variability call for a better understanding of the processes driving the SST variability. On the highfrequency part of its spectrum, we find the diurnal SST variations of which the diurnal cycle of solar radiation due to the earth's rotation (Sverdrup et al. 1942; Roll 1965 ) is the leading-order cause. While SST anomalies on intraseasonal to interannual time scales can reach approximately $1^{\circ} \mathrm{C}$, diurnal variations can reach $3^{\circ} \mathrm{C}$ in the tropics (Fairall et al. 1996; Soloviev and Lukas 1997) and even reach $6^{\circ}-8^{\circ} \mathrm{C}$ in the Atlantic Ocean and in the Mediterranean Sea in extreme cases (Gentemann et al. 2008; Merchant et al. 2008). Large ocean diurnal warmings can cover regions extending up to $1000 \mathrm{~km}$ (Gentemann et al. 2008).

\section{b. The ocean mixed layer diurnal cycle}

The diurnal variations in mixed layer depth results from the competition between stabilizing processes like the absorption of solar heat flux and destabilizing processes such as convective and shear-driven turbulent mixing. During the night, as no solar heat flux reaches the surface, the density profile is mixed with underlying layers and the mixed layer reaches its greatest depth just before sunrise. The sunrise causes a rapid shoaling of the mixed layer that accelerates the warming of the surface as the absorbed heat is mixed on a shallower and shallower layer. The minimum in mixed layer depth occurs at about midday and the maximum in sea surface temperature at around 1500 local time. During the day, the penetration of solar heat flux also contributes to build a stable stratification below the mixed layer. As the sun goes down, the stabilizing effect of the solar heat flux decreases and the stratification below the mixed layer is slowly eroded. As the mixed layer deepens, its heat content is mixed downward and the sea surface temperature decreases. The turbulent mixing intensifies during the night and the stratification builtup during the day is more or less eroded depending on the intensity of the nonsolar heat flux and the wind stress.

Diurnal SST variations are therefore primarily induced by the atmospheric forcing, in particular by the solar heat flux. The surface response to this forcing is far from being linear as the vertical mixing in the ocean redistributes the input heat with an amplitude depending on the intensity of turbulence. The level of turbulence depends on the balance between the competing effects of the precipitation and the solar heat flux on the one hand, which tend to stratify the upper ocean, and the wind stress, the nonsolar heat flux, and the evaporation on the other hand (Soloviev and Lukas 2006). The nonlinearity of the SST response to the atmospheric forcing implies that the daily mean impact of the atmosphere on the ocean can potentially not be reduced to the impact of the daily mean atmosphere on the ocean.

\section{c. Climate impacts of the ocean diurnal cycle in the tropics}

In the tropics, the ocean diurnal warming can induce an increase in the net surface heat flux toward the atmosphere of more than $50 \mathrm{~W} \mathrm{~m}^{-2}$ during the day, under clear-sky, and calm conditions (Fairall et al. 1996; Ward 2006). Hence, the diurnal cycle of the ocean surface can impact the atmosphere and take part in atmosphereocean coupling mechanisms. For instance, the SST diurnal variations can affect the life cycle of tropical convective clouds (Chen and Houze 1997; Woolnough et al. 2000; Dai and Trenberth 2004) and the atmospheric profiles of heat, moisture, and cloud properties (Clayson and Chen 2002). Furthermore, recent studies suggest that resolving the SST variability on diurnal time scales can significantly modulate the amplitude of SST variability on intraseasonal time scales (Shinoda and Hendon 1998; Bernie et al. 2005; Shinoda 2005; Bernie et al. 2007; Bellanger 2007) or even decadal time scales (Danabasoglu et al. 2006) and improve the representation of ocean-atmosphere coupled modes of variability, such as the Madden-Julian oscillation by modifying its 


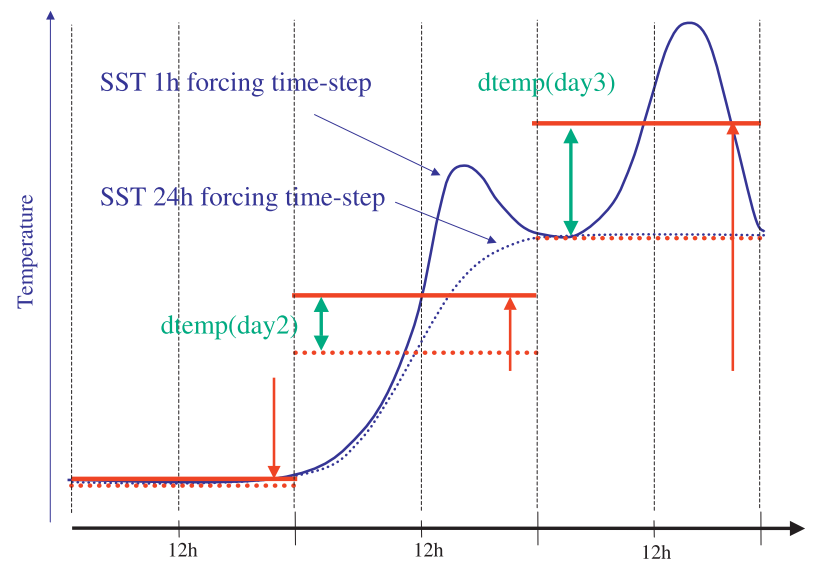

FIG. 1. Schematic summarizing Bernie et al. (2005) and Shinoda's (2005) rectification mechanism. The continuous line is the experiment forced every hour; dotted line is the experiment forced every day; horizontal lines are daily mean SSTs; red arrows are differences between the daily mean temperature in the experiment forced on a hourly time step and its seasonal mean; and green arrows are $\Delta \overline{\mathrm{SST}}=$ differences between the daily mean temperature in the experiment forced on a hourly time step and in the experiment forced on a daily time step.

phase (Woolnough et al. 2007) and the amplitude of the SST anomalies (Bernie et al. 2005, 2008) or of the ENSO by changing its frequency spectrum (Danabasoglu et al. 2006).

Shinoda and Hendon (1998) and Bernie et al. (2005) suggest a mechanism, called the "rectification" mechanism and illustrated in Fig. 1, to explain the impact of the ocean diurnal cycle on the intraseasonal SST variability in the tropics. The SST time series in blue correspond to a simulation forced every hour (continuous line) and a simulation forced every day (dotted line). The daily mean temperatures of each experiment are plotted in red as segment lines covering the whole day. For Shinoda and Hendon (1998) and Bernie et al. (2005), the night temperature is roughly the same whenever the ocean diurnal cycle is taken into account or not. Thus, the two simulations differ mostly during daytime. During the day, the shallow mixed layer in the afternoon is associated with a peak in temperature so that the daily mean temperature is higher if the diurnal cycle is taken into account (continuous line) than if not (dotted line). The difference in daily mean temperature between both experiments is represented by a green arrow on Fig. 1 and is defined as $\Delta \overline{\mathrm{SST}}$. The larger the diurnal warming, the larger $\Delta \overline{\mathrm{SST}}$ is. This result relies on the hypothesis that the turbulent mixing is strong enough during the night to totally clear the mixed layer memory and the mixed layer is shallow enough during the day so that the stratification is easily eroded during the following night. Consequently, the temperature profiles of the two experiments are the same during the night. This behavior of the ocean column is demonstrated by Shinoda (2005) by performing a heat and turbulence budget at the Improved Meteorological Instrument (IMET) mooring site $\left(1.45^{\circ} \mathrm{S}, 1.56^{\circ} \mathrm{E}\right)$ during the Tropical Ocean and Global Atmosphere Coupled Ocean-Atmosphere Response Experiment (TOGA COARE) (Webster and Lukas 1992).

Bernie et al. (2005) and Shinoda (2005) focused on a region where the intraseasonal variability is dominated by the MJO $\left(1.45^{\circ} \mathrm{S}, 1.56^{\circ} \mathrm{E}\right)$. Bernie et al. (2005) used a one-dimensional model incorporating the $K$-profile parameterization from Large et al. (1994) while Shinoda (2005) used the one-dimensional model developed by Price et al. (1986). On the one hand, the days during which the cloud cover is sparse have large surface solar irradiance and their daily mean temperature (in red) is higher than its seasonal mean (red arrow). These days are also days for which the diurnal warming is large and $\Delta \overline{\mathrm{SST}}$ (green arrow) is high, which means that the daily mean temperature is higher if the ocean diurnal cycle is simulated. On the other hand, the days having weak surface solar irradiance are days for which the daily mean temperature (in red) is lower than its seasonal mean (red arrow). These days are also days that there is no diurnal warming and $\Delta \overline{\mathrm{SST}}$ is 0 . Consequently, the days of positive anomaly in surface temperature relative to the seasonal mean (red arrow) are also days that $\Delta \overline{\mathrm{SST}}$ is high (green arrow). Days of negative anomaly in surface temperature are days that $\Delta \overline{\mathrm{SST}}$ equals 0 . As a result, the variability in daily surface temperature is larger in the experiment taking into account the ocean diurnal cycle (red continuous lines) than in the experiment that does not (red dotted lines). Thus, taking into account the ocean diurnal cycle acts to enhance the intraseasonal variability. Shinoda and Hendon (1998) quantify this enhancement to about $20 \%$ while Bernie et al. (2005) quantify it to $40 \%$. This result is illustrated by Fig. 3 in Bernie et al. (2005). In a following study, Bernie et al. (2007) used an ocean general circulation model with high vertical resolution ( $1 \mathrm{~m}$ near the surface) to confirm the $20 \%$ increase of the intraseasonal SST variability when representing the ocean diurnal cycle in the $5^{\circ} \mathrm{S}-5^{\circ} \mathrm{N}, 60^{\circ} \mathrm{E}-180^{\circ}$ region.

\section{d. Climate impacts of the ocean diurnal cycle in the midlatitudes}

Using satellite data, Kawai and Wada (2007) show that the average diurnal warming amplitude, computed from skin temperature, is about $0.75^{\circ} \mathrm{C}$ year-round in the tropics but also exceeds $0.75^{\circ} \mathrm{C}$ in most of the midlatitudes in summer. Using drifting buoys, Kennedy et al. (2007) show that the diurnal warming amplitude, computed from 25 -cm-depth temperature, is rather about $0.5^{\circ} \mathrm{C}$ year-round in the tropics but also reaches $0.5^{\circ} \mathrm{C}$ in 
the midlatitudes in summer. The differences between both studies can be explained by the strong temperature gradient in the uppermost meter of the ocean (Yokoyama et al. 1995; Soloviev and Lukas 1997; Ward 2006; Kawai and Wada 2007). Deschamps and Frouin (1984) found events with diurnal warming amplitudes of more than $3^{\circ} \mathrm{C}$ in the Mediterranean Sea. Flament et al. (1994) showed that the diurnal warming amplitude can exceed $6^{\circ} \mathrm{C}$ near California. Cornillon and Stramma (1985) and Stramma et al. (1986) observed diurnal warming amplitudes of $4^{\circ} \mathrm{C}$ near the Azores. Gentemann et al. (2008) list values of extreme diurnal warming, as registered by the Moderate Resolution Imaging Spectroradiometer (MODIS) satellite, of $5.9^{\circ} \mathrm{C}$ east of Newfoundland, $7.1^{\circ} \mathrm{C}$ near the east American coast, and $7.0^{\circ} \mathrm{C}$ near the Iberian Peninsula. Merchant et al. (2008) found extreme diurnal warmings of $6^{\circ} \mathrm{C}$ in the Mediterranean Sea using the European Organisation for the Exploitation of Meteorological Satellites (EUMETSAT) satellite data. They also found events of diurnal warming exceeding $4^{\circ} \mathrm{C}$ over extents of about $40 \mathrm{~km}$. For Gentemann et al. (2008), diurnal warming events with a peak amplitude between $5^{\circ}$ and $7^{\circ} \mathrm{C}$ can be spatially coherent over areas extending up to $1000 \mathrm{~km}$. With such a large scale, these extreme diurnal warmings could affect climate variability on longer time scales. Furthermore, Gentemann et al. (2008) showed that most of the extreme diurnal warmings occur in the summer midlatitudes, not in the tropics, because summer midlatitudes undergo lighter winds than the tropics.

Using the National Oceanic and Atmospheric Administration (NOAA) Advanced Very High Resolution Radiometer (AVHRR) satellite data, Cornillon and Stramma (1985) showed an example for the North Atlantic where the monthly mean SST was higher by about $0.2^{\circ} \mathrm{C}$ in the case diurnal SST variations were taken into account compared to the case in which they were ignored. This difference reduces the daily average net heat flux entering the ocean by about $5 \mathrm{~W} \mathrm{~m}^{-2}$.

The studies presented above show that the ocean diurnal cycle can have an impact on the intraseasonal variability in the tropics. The most recent studies, showing large diurnal warmings in the midlatitudes, imply a potential extension of the role of the ocean diurnal variations demonstrated in the tropics to the midlatitudes and highlight a need for a better understanding of the processes controlling the interactions between the diurnal SST variations and SST variability on longer time scales in this region.

\section{e. Aim of this study}

The most recent oceanic and atmospheric general circulation models used to produce climate simulations still exchange data once a day. Thus, the diurnal cycle simulated in the atmosphere is not transmitted to the ocean that receives daily mean forcings, and the ocean diurnal variations are not modeled. The studies cited above show that this simplification could bias the SST variability and the estimations of the surface heat fluxes on intraseasonal time scales. Here, we aim at diagnosing the amplitude of the correction in daily mean SST induced by the representation of the ocean diurnal cycle along with the persistence of this correction. We then investigate the nonlinear processes due to turbulent mixing by which the ocean diurnal variations affect the daily mean SST and in turn the surface heat fluxes in the midlatitudes. Most of the previous studies on the ocean diurnal cycle have focused on the tropics, we extend these analyses to the midlatitudes. These analyses are conducted by comparing two simulations run with a one-dimensional turbulent kinetic energy (TKE) ocean model based on the parameterization from Gaspar et al. (1990), forced with the 40-yr European Centre for Medium-Range Weather Forecasts (ECMWF) ReAnalysis (ERA-40) atmospheric data (Gibson et al. 1997; Uppala et al. 2004) (http://www.ecmwf.int/products/data/ technical/index.html). One simulation resolves the ocean diurnal variations with a forcing frequency of $1 \mathrm{~h}$ while the other is forced with a frequency of 1 day as in coupled ocean-atmosphere general circulation models.

The paper is organized as follows. The ocean model and the forced simulations are presented in section 2 . Section 3 presents diagnostics of the role of the ocean diurnal variations on the SST variability on intraseasonnal time scales and seeks factors that can be involved in such an interaction. Section 4 presents idealized sensitivity experiments designed to investigate the physical processes by which the ocean diurnal variability can affect the daily mean SST. Section 5 and 6 are dedicated to discussions and conclusions, respectively.

\section{Model and simulations}

The ocean model used in this study is the Centre National de Recherches Météorologiques one-dimensional Ocean Model (CNRMOM1D). The sea ice model Global Experimental Leads and Sea Ice Model for Atmosphere and Ocean (GELATO3) (Salas-Mélia 2002), used in a thermodynamic mode, is embedded in CNRMOM1D. This ocean-sea ice model is driven by surface fluxes from ERA-40 over the 1959-2001 period.

\section{a. The CNRMOM1D}

The CNRMOM1D is based on the vertical mixing scheme developed by Bougeault and Lacarrère (1989) 
for the atmospheric boundary layer and adapted to the ocean by Gaspar et al. (1990). In this formulation, the vertical mixing coefficients are based on the calculation of two turbulent length scales representing the upward and downward conversions of turbulent kinetic energy into potential energy. The second-order moments are expressed as a function of the turbulent kinetic energy, which is computed via a prognostic equation. This 1.5 turbulence closure parameterization has been validated against observational data from buoys at diurnal to interannual time scales in various locations, for example, at stations Papa $\left(50^{\circ} \mathrm{N}, 145^{\circ} \mathrm{W}\right)$, the Long Term Upper Ocean Study (LOTUS, $34^{\circ} \mathrm{N}, 70^{\circ} \mathrm{W}$ ), and buoy Marisonde launched at $1^{\circ} \mathrm{S}$ and $156^{\circ} \mathrm{E}$ during the TOGA COARE campaign (Gaspar et al. 1990). Gaspar et al. (1990) show that the amplitude of the diurnal cycle and the amplitude of the SST variations on daily time scales in the Sargasso Sea $\left(34^{\circ} \mathrm{N}, 70^{\circ} \mathrm{W}\right)$ computed by this turbulent mixing scheme are realistic. The temporal incrementation follows an implicit scheme, which guarantees the temporal stability of the model. This initial model core has been embedded in more complex models and used in oceanographic studies such as those of Caniaux et al. (2005) focusing on surface flux estimates and Giordani et al. (2005a,b, 2006) focusing on the assimilation of geostrophic currents, the heat budget, and the vertical velocity in the oceanic upper layers during the Programme Océan Multidisciplinaire Méso-Echelle (POMME) experiment, respectively.

The vertical profile of solar absorption is a crucial point in the representation of the stabilization processes in the upper ocean. The parameterization of solar absorption therefore plays a major role in the representation of the diurnal cycle of SST (Kantha and Clayson 1994; Sui et al. 1997; Ward 2006). Shinoda (2005) showed that the diurnal warming amplitude, defined as the difference between the daily maximum and nocturnal minimum temperatures, can turn out to be twice as high between two different water types, as described by Jerlov (1976), when solar absorption is parameterized according to Paulson and Simpson (1977). Recently, Ohlmann (2003) developed a new parameterization of the solar transmission function depending on the chlorophyll concentration. Ohlmann's (2003) results show that the bias in the solar transmission profile can be reduced by $50 \%-90 \%$ compared to the Paulson and Simpson (1977) parameterization. Ohlmann's (2003) parameterization has been implemented in the CNRMOM1D to optimize the representation of the diurnal cycle of SST. The chlorophyll concentration was specified as a 12-month climatology derived from satellite ocean color measurements from the Sea-Viewing Wide Field-ofView Sensor (SeaWIFS) project.
As this model does not take into account advective processes, it is much less computationally expensive than three-dimensional ocean models resolving all physical and dynamical processes. This allows it to perform simulations with a high horizontal and vertical resolution. The model has been run on a regular T159 grid, equivalent to horizontal resolution of $1.125^{\circ}$. The choice of the vertical resolution is based on the results from Bernie et al. (2005). They performed a sensitivity study of the diurnal warming amplitude simulated by the Large et al.'s (1994) K-Profile Parameterization (KPP) ocean model to its vertical resolution. The diurnal warming amplitude increases rapidly with top layers vertical resolution, up to a critical value in model level thickness of $1 \mathrm{~m}$. The simulated diurnal warming amplitude then saturates (their Fig. 10) for numerical reasons. We obtain the same results with the CNRMOM1D. This saturation reflects the limits of using parameterizations like KPP or TKE, which were developed for a lower resolution than the one necessary to perform studies of the upper-ocean fine structures on centimeter scales. These parameterizations are not able to reproduce the small-scale downward diffusion of nonsolar heat flux. Supplementary developments would be necessary to reproduce a more realistic thermodynamic profile on centimeter scales. However, compared to the 10-m scale of the actual ocean models used to run climate simulations, running an ocean model on the meter-scale constitutes a first important step in quantifying the improvements that could be made in simulating the intraseasonal SST variability if increasing the vertical resolution. An extensive quantification of the impact of the ocean diurnal cycle will be possible when we can afford centimeter-scale climate studies. In agreement with the results from Bernie et al. (2005), we use 124 vertical levels in the CNRMOM1D with enhanced resolution near the sea surface, where the level thickness reaches $1 \mathrm{~m}$ down to $75-\mathrm{m}$ depth and then increases up to a 500-m-level thickness at the ocean bottom.

\section{b. The simulations}

The simulations cover the 1959-2001 period, corresponding to the period of ERA-40. Downwelling radiative fluxes and precipitation are directly taken from ERA-40. Following the recommendations by Ramos Buarque et al. (2004), the heat and water fluxes lagging the assimilation process by $12 \mathrm{~h}$ were chosen to avoid biases due to the spinup of the atmospheric model. The turbulent fluxes are computed based on the Exchange Coefficients from Unified Multicampaigns Estimates (ECUME) bulk formulae for the ice-free ocean (Belamari 2005; Belamari and Pirani 2007) using the 2-m air temperature, surface pressure, specific humidity, and wind speed from ERA-40. Over sea ice, turbulent heat 
fluxes are computed according to the Simonsen and Haugan (1996) formulation with a constant exchange coefficient set at $1.75 \times 10^{-3}$ (Maykut 1982). The temporal resolution of ERA-40 is $6 \mathrm{~h}$. Following the recommendations of Bernie et al. (2005), a forcing frequency of at least $3 \mathrm{~h}$ for the downwelling shortwave heat flux is needed to obtain a good representation of the diurnal cycle. Tests with a 3 -h resolution were not satisfactory as a 3-h-period wave appeared around the globe in the climatology of diurnal warming amplitude. Thus, to get more satisfactory results, a forcing frequency of $1 \mathrm{~h}$ was chosen for the first simulation, named ERA1h, designed to resolve the diurnal cycle. To resample the shortwave flux to an hourly basis, the same method as in Bernie et al. (2007) has been used, except that hourly downwelling shortwave heat fluxes were computed from the 6-h resolution instead of the daily mean fluxes. This method consists in an energy-conserving interpolation using trigonometrical functions depending on the latitude and the season. Detailed explanations about this method are given in appendix A of Bernie et al. (2007). The ERA1h ocean-sea ice simulation was run by forcing the oceansea ice model with a temporal resolution of $6 \mathrm{~h}$ for all other surface fluxes. The sensitivity experiment, named ERA24h, was run by forcing the ocean-sea ice model with a temporal resolution of 1 day for all surface fluxes. In this simulation, the turbulent fluxes are computed via the ECUME bulk formulae using daily averages of sea surface temperatures, and the other fluxes are daily averages of ERA-40 surface fluxes.

The simulations are initialized from the Polar Science Center Hydrographic Climatology (PHC) (Steele et al. 2001) for temperature and salinity. PHC merges the 1998 version of the World Ocean Atlas (Antonov et al. 1998) with the new regional Arctic Ocean Atlas (Environmental Working Group 1997a,b) and improves the description of the Arctic Ocean and its peripheral seas compared to the Levitus data (http://www.esrl.noaa.gov/ $\mathrm{psd} /$ data/gridded/data.nodc.woa98.html). To obtain a realistic initial state for sea ice, the ocean-sea ice coupled model is run for 1 year with an initial sea ice extent taken from the Met Office Hadley Centre Sea Ice and SST dataset (HadISST) (Rayner et al. 2003) (http:// badc.nerc.ac.uk/data/hadisst/) and ice thickness set at $3 \mathrm{~m}$ in the Arctic Ocean and $1 \mathrm{~m}$ around Antarctica. During the year 1958, the ocean state is relaxed toward PHC with an $e$-folding time scale of 1 day. This year is thus considered as a spinup year and is removed. Then, the sea ice model evolves freely.

As the advective and horizontal diffusive processes are not represented in the one-dimensional ocean model, three-dimensional heat and freshwater flux corrections are needed to obtain a stable mean state. To compute these flux corrections, the ocean model state is forced with a relaxation of temperature and salinity toward PHC (Steele et al. 2001) with an $e$-folding time scale of 1 day during the whole 1958-2001 period. Relaxation trends in temperature and salinity are saved at each time step. A daily climatology of these trends is computed for the 1959-2001 period. The year 1958 is considered as a spinup and removed to compute these heat and freshwater flux corrections. This method is applied once with a forcing frequency of $1 \mathrm{~h}$ to produce the flux corrections adapted to the ERA1h experiment and once with a forcing frequency of 1 day to produce the flux corrections adapted to the ERA24h experiment. These three-dimensional climatologies are then applied as three-dimensional heat and freshwater flux corrections to obtain a second pair of simulations for the 1959-2001 period (ERA1h and ERA24h), which are the simulations studied here. In this second set of simulations, the ocean state is relaxed toward PHCs with an $e$-folding time scale of 365 days, which corresponds to a $0.12 \mathrm{~W} \mathrm{~m}^{-3} \mathrm{~K}^{-1}$ heat flux. In the $2.5^{\circ} \mathrm{S}-$ $2.5^{\circ} \mathrm{N}$ band, the $e$-folding time scale is set to 1 day, which corresponds to a $47.41 \mathrm{~W} \mathrm{~m}^{-3} \mathrm{~K}^{-1}$ heat flux. Indeed, the variability of the advection plays a key role on the intraseasonal SST variability in this region. The $e$-folding time scale decreases linearly between these values in the $5^{\circ} \mathrm{S}-2.5^{\circ} \mathrm{S}$ and $2.5^{\circ}-5^{\circ} \mathrm{N}$ bands. These latitudes will not be studied in our analyses and will be shaded out on the figures. Using this method, we obtain stable ERA1h and ERA24h simulations.

\section{c. Validation}

The three-dimensional flux correction is applied to account for missing physics in the ocean such as transport by the mean currents. The integration of the heat flux correction along the vertical for the Atlantic Ocean (Figs. 2a,b) shows the compensation for horizontal advection along the Gulf Stream and the equatorial cold tongue and associated upwellings. The heat flux correction associated with the transport by the Gulf Stream amounts to about $100 \mathrm{~W} \mathrm{~m}^{-2}$ in summer and $200 \mathrm{~W} \mathrm{~m}^{-2}$ in winter. The coastal upwellings near Africa are represented by a heat flux of about $-100 \mathrm{~W} \mathrm{~m}^{-2}$ year-round. Heat is redistributed from the tropics toward higher latitudes. In the Northern Hemisphere, more heat is added in winter (November-March) than in summer (May-September). For example, in the northern high latitudes, the heat flux correction reaches about 200 $300 \mathrm{~W} \mathrm{~m}^{-2}$ in winter and $-50 \mathrm{~W} \mathrm{~m}^{-2}$ in summer. These patterns of heat flux correction are close to the ones obtained by Cassou et al. (2007) for their ocean mixed layer model (see their Fig. 1). The integration of the freshwater flux correction along the vertical (Figs. 2c,d) 
a) MJJAS Heat Flux correction

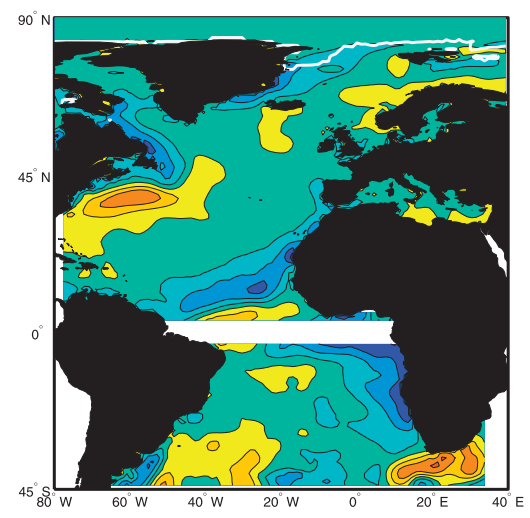

c) MJJAS Salt Flux correction

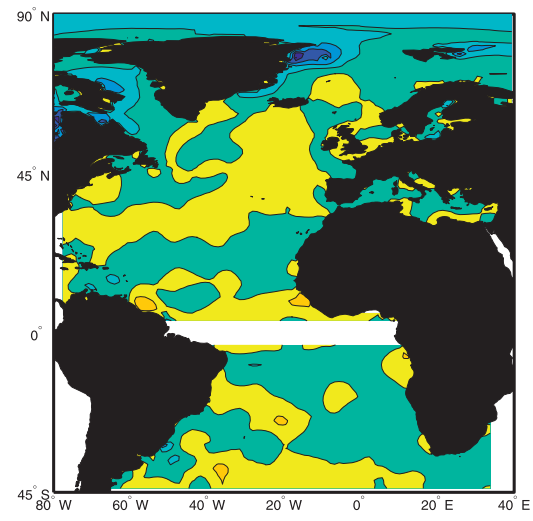

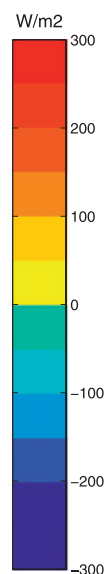

$\mathrm{mm} / \mathrm{month}$

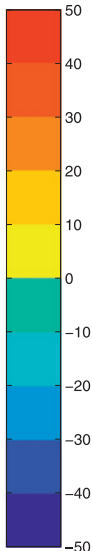

b) NDJFM Heat Flux correction

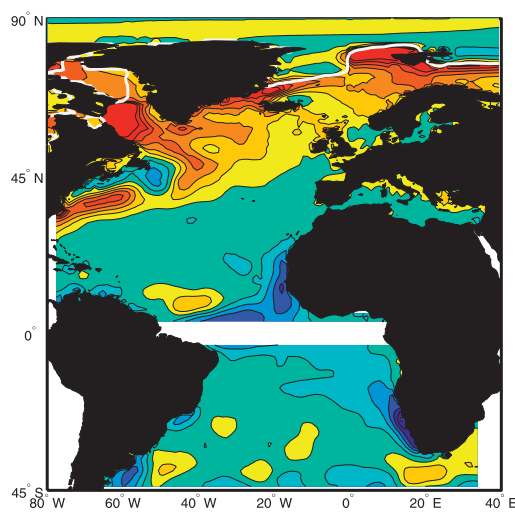

d) NDJFM Salt Flux correction

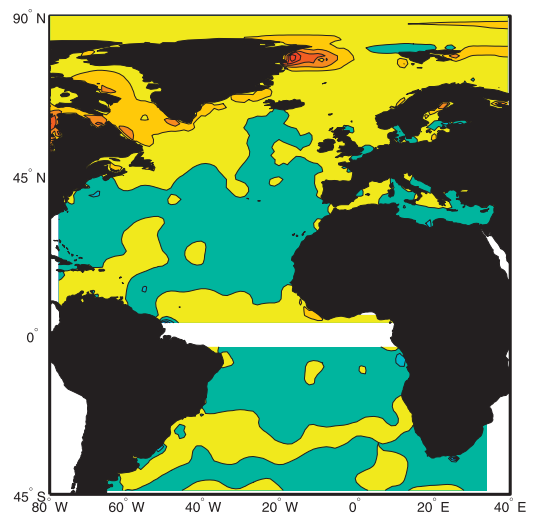

$\mathrm{W} / \mathrm{m} 2$

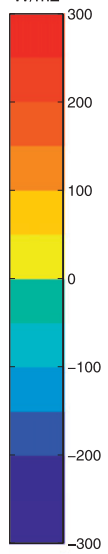

$\mathrm{mm} / \mathrm{month}$

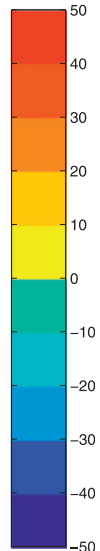

FIG. 2. Three-dimensional heat flux correction integrated over the vertical for extended (a) summer (MaySeptember) and (b) winter (November-March) seasons. Contour interval is $50 \mathrm{~W} \mathrm{~m}^{-2}$. White contours give the mean sea ice extent defined as the $90 \%$ sea ice concentration limit. Three-dimensional freshwater flux correction integrated over the vertical for extended (c) summer (May-September) and (d) winter (November-March) seasons. A positive flux contributes to an increase in temperature or in salinity. Contour interval is $10 \mathrm{~mm} \mathrm{month}{ }^{-1}$.

shows the extraction of salt from the Mediterranean Sea by about $-5 \mathrm{~mm} \mathrm{day}{ }^{-1}$. Under sea ice, salt is extracted (added) in summer (winter) with a freshwater flux correction of about $-10 \mathrm{~mm} \mathrm{day}^{-1}\left(+10 \mathrm{~mm} \mathrm{day}^{-1}\right)$, down to $-40 \mathrm{~mm} \mathrm{day}^{-1}$ (up to $+40 \mathrm{~mm} \mathrm{day}^{-1}$ ) in the Greenland Sea. Strong heat and freshwater fluxes at high latitudes account for the missing dynamical processes in the ice and ocean model, such as advection of cold and freshwater from Davis Strait in summer. The winter sea ice extent is close to the Hadley Centre 1959-2001 climatology (http://badc.nerc.ac.uk/data/hadisst/, not shown) except in the Labrador Sea. The area of maximum heat flux correction corresponds to a lack of sea ice according to the HadISST data. This reflects an inconsistency between the PHC and ERA-40 data, and we cannot assess the realism of these fluxes.

The ERA1h large-scale patterns of winter [DecemberFebruary (DJF)] and summer [June-August (JJA)] mixed layer depth (MLD), defined as the depth at which the density difference from the sea surface is $0.03 \mathrm{~kg} \mathrm{~m}^{-3}$, (Figs. 3a,b) look similar to the observations from De Boyer-Montégut et al. (2004) (Figs. 3c,d). However, on average the mixed layer depth is too small compared to the observations by about $5-10 \mathrm{~m}$ in summer and about $10-50 \mathrm{~m}$ in winter because of the too weak turbulent mixing. In summer the underestimation represents about $30 \%$ of the seasonal mean. The winter mixed layer depth maxima, corresponding to deep convection sites, are properly reproduced by the ocean model apart from small shifts in locations, a smaller extent, and a lower maximum depth. The storm track crossing the North Atlantic Ocean affects the turbulent mixing at mid- to high latitudes in the model as well as in the observations. Even if the intensity of the turbulent mixing is underestimated, the realistic spatial variability of the mixed layer depth reflects its realistic sensitivity to variations in surface 
a) JJA mean mixed layer depth in ERA1h

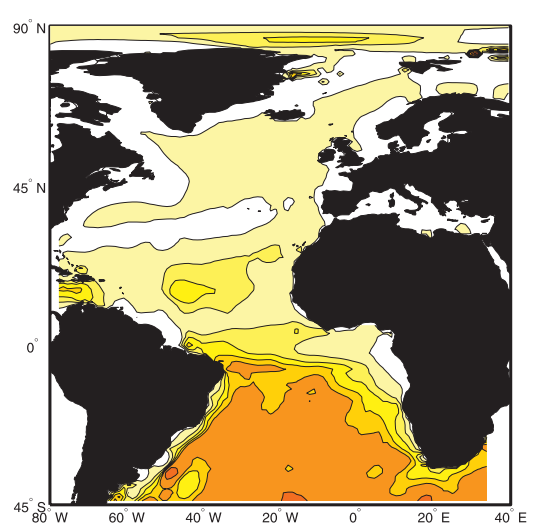

c) JJA MLD from De Boyer Montegut (2004)

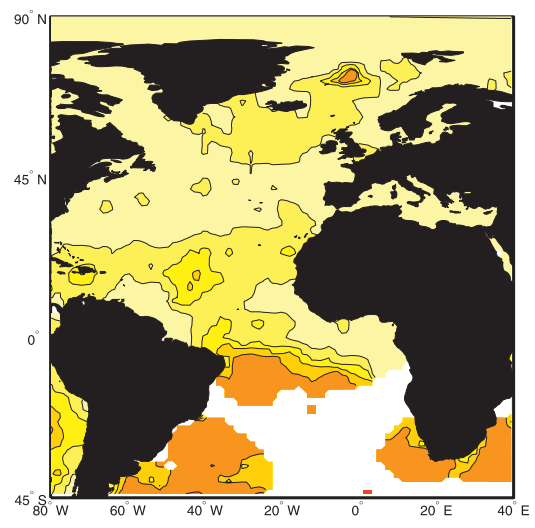

b) DJF mean mixed layer depth in ERA1h

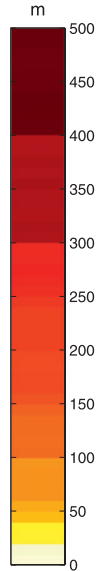

m

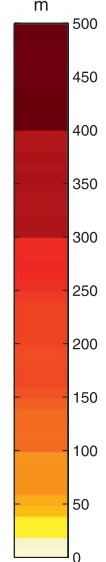

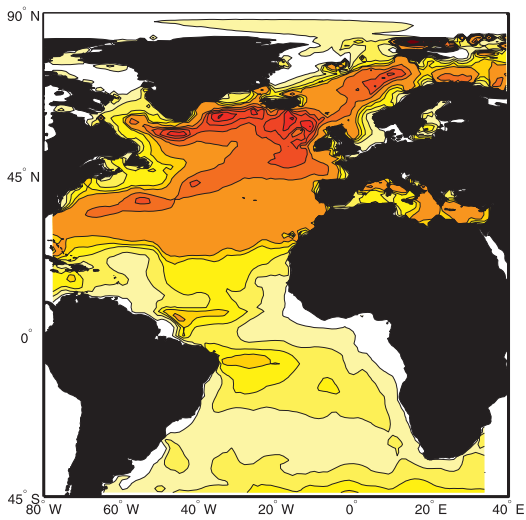

d) DJF MLD from De Boyer Montegut (2004)

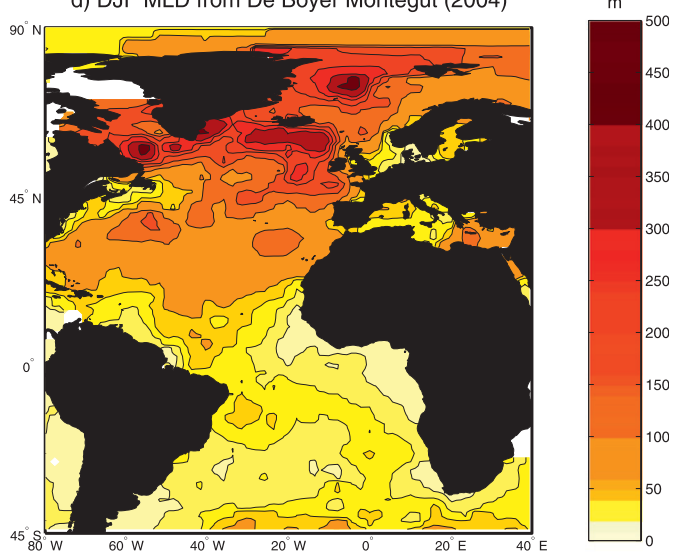

FIG. 3. Mean (a),(c) summer (June-August) and (b),(d) winter (December-February) mixed layer depth in the CNRMOM1D/GELATO ERA1h forced simulation (see details in the text) in the climatology from De BoyerMontégut et al. (2004). Contour interval is 10 below $50 \mathrm{~m}, 50$ between 50 and $300 \mathrm{~m}$, and $100 \mathrm{~m}$ above. The masked area in (c) corresponds to missing values in the observations.

forcings. The good agreement between the observed and simulated patterns of mixed layer depth reflects the ability of the model to account for the main key mechanisms controlling the mixed layer heat content.

A basinwide average bias of about $0.5^{\circ} \mathrm{C}$ (Fig. 4) in ERA1h SST compared to the PHC (Steele et al. 2001) is found in summer [May-September (MJJAS)]. This bias may be ascribed to the shallower-than-observed MLD. The largest difference between the SST in ERA1h and in the PHC data occurs in the coastal tropical upwellings where it can reach $2^{\circ} \mathrm{C}$. The cold bias in winter [November-March (NDJFM)] in the Labrador Sea reflects the too large sea ice extent according to PHC data. This may also be due to an inconsistency between PHC and ERA-40 data. The intraseasonal SST variability as simulated by this model is presented in Guemas et al. (2010) where typical patterns of daily SST anomalies persisting for about one week are compared to the patterns given by NOAA satellite data (Reynolds et al.
2007). The model performances are satisfactory except along the American coast, where the bias in daily SST anomalies can reach $0.3^{\circ} \mathrm{C}$.

As this study focuses on the surface temperature diurnal variations, it is essential to know if the diurnal surface warming is correctly reproduced by CNRMOM1D. To this aim, we use the LOTUS mooring (Briscoe and Weller 1984) data in the Sargasso Sea $\left(34^{\circ} \mathrm{N}, 70^{\circ} \mathrm{W}\right)$ for the period 12-25 July 1982. The surface forcing fluxes are computed from observations as described in Gaspar et al. (1990) (net surface heat flux correction of $-71 \mathrm{~W} \mathrm{~m}^{-2}$ ) and the model is initially at rest, the temperature profile taken as the observed one, and a vertically uniform salinity equal to 36.3 practical salinity unit (psu). The chlorophyll concentration is taken equal to $0.092 \mathrm{mg} \mathrm{m}^{-3}$, which corresponds the mean value in July in this area. The simulated SST time series (Fig. 5) compares quite well to the observed one despite a cold bias of about $1^{\circ} \mathrm{C}$. The simulated diurnal warming amplitude 
a) MJJAS SST deviation from $\mathrm{PHC}(2001)$

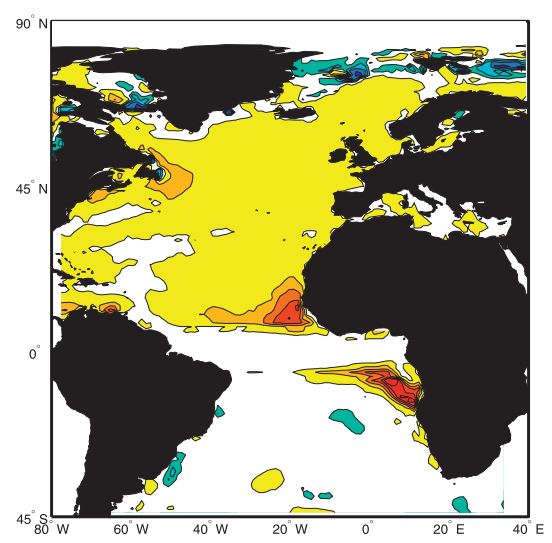

$\mathrm{C}$

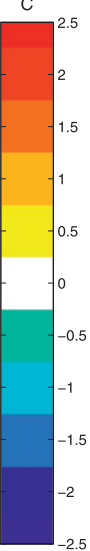

b) NDJFM SST deviation from PHC (2001)

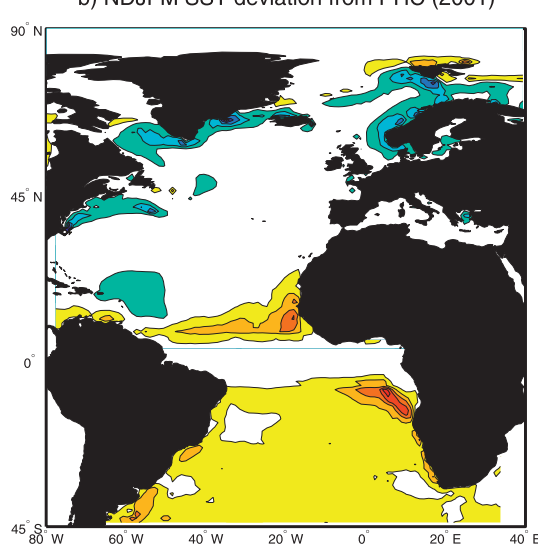

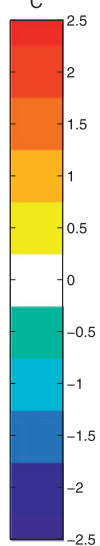

FIG. 4. Mean (a) summer (May-September) and (b) winter (November-March) differences between the sea surface temperature in the CNRMOM1D/GELATO ERA1h forced simulation and the PHC (Steele et al. 2001) data. Contour interval is $0.5^{\circ} \mathrm{C}$.

is too small, but its time evolution closely follows the observed one.

We now focus on the diurnal warming amplitude in ERA1h. The simulated time of the diurnal minimum in SST is close to sunrise and the time of the diurnal maximum in SST is around 1500 local time. The diurnal warming of each day is defined as the difference between the absolute maximum occurring between 1030 and 1800 local time and the preceeding absolute minimum occurring between 1800 and 1030. In case there is no local extremum in these time windows, the diurnal warming is set to zero. The simulated patterns of mean winter (DJF) and summer (JJA) diurnal-warming amplitude (Fig. 5) resemble the ones obtained by Kawai and Wada (2007) from the skin temperature given by satellite data covering June 2002-May 2006 (see their Fig. 5) and the ones obtained by Kennedy et al. (2007) using $25-\mathrm{cm}$-depth temperature given by drifting buoys. A wave with a period of $1 \mathrm{~h}\left(15^{\circ}\right)$ corresponding to the forcing resolution appears. The diurnal warming is larger in summer than in winter. It is around $0.3^{\circ} \mathrm{C}$ with maxima of about $0.5^{\circ} \mathrm{C}$ in the subtropical high, and it is around $0.5^{\circ} \mathrm{C}$ with maxima of about $0.7^{\circ} \mathrm{C}$ along the American coast and the Mediterranean Sea during summer while it is less than $0.1^{\circ} \mathrm{C}$ in winter. Regions of strong westerlies or strong easterlies have a weak diurnal warming compared to surrounding areas as a strong wind stress enhances the turbulent mixing and prevents the diurnal shoaling and warming of the mixed layer. However, the simulated amplitude is about twice as small as the one given by Kawai and Wada (2007). We can explain this discrepancy by the fact that in our model we define the SST as the 50-cm-depth temperature, while satellite observations such as the ones used by Kawai and Wada measure the skin temperature. Indeed, a sharp gradient in temperature can occur in the first meter (Yokoyama et al. 1995; Soloviev and Lukas 1997; Ward 2006; Kawai and Wada 2007) during daytime. Furthermore, the simulated amplitude is close to the 25-cm-depth amplitude obtained by Kennedy et al. (2007) even if the computation depth is not the same. This is surprising as we would also expect a temperature gradient between the 25- and $50-\mathrm{cm}$ depths and a smaller diurnal warming amplitude in our experiment than in Kennedy et al. (2007). So, the present model seems to slightly overestimate the simulated diurnal warming amplitude compared to Kennedy et al. (2007) data. At this point, it is hard to conclude about the model performances in simulating the correct amplitude of the diurnal warming at 50-cm depth since it is not precisely known. Further validation of CNRMOM1D can be found in the supplemental material.

\section{Modulation of the intraseasonal SST variability by the diurnal variability}

\section{a. Method for the analysis of the impact of the ocean diurnal variations}

As flux corrections were specifically computed for each experiment, ERA1h and ERA24h, using the same reference for the ocean thermodynamic state, their mean state is constrained to be the same. Indeed, the differences in mean sea surface temperatures between ERA1h and ERA24h are not significant (not shown). These experiments are designed to analyze the impact of the ocean diurnal variations on the intraseasonal variability rather than on the mean state.

The time series of daily mean SST are computed at each grid point for both the ERA1h and ERA24h experiments. The comparison of these two daily SST 

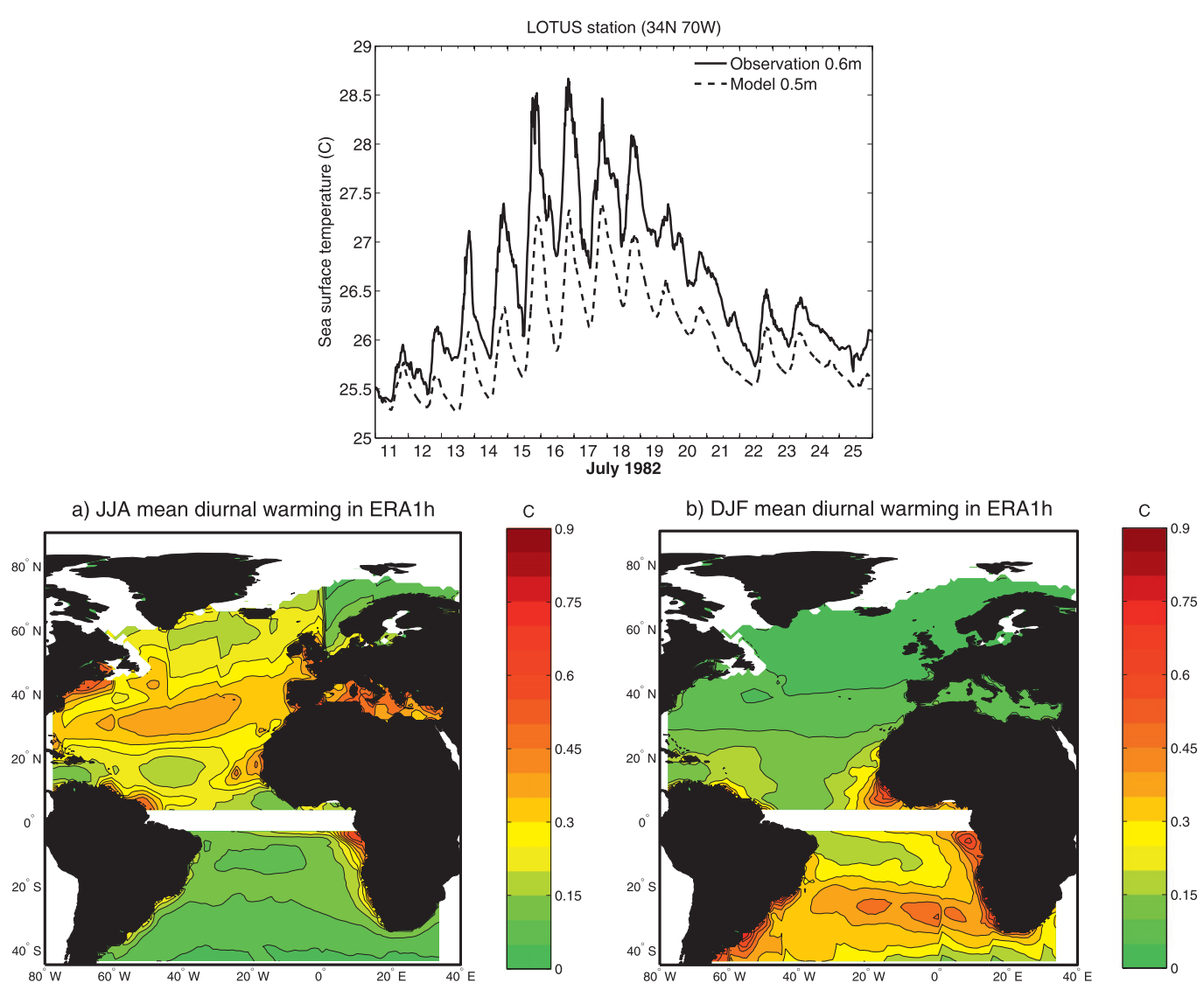

FIG. 5. (top) Observations of the ocean temperature at $0.6 \mathrm{~m}$ (solid curve) compared with the temperatures simulated at $0.5 \mathrm{~m}$ (dashed curve) at the LOTUS station during the 12-26 Jul 1982 period. (bottom) (a) Mean summer (June-August) and (b) winter (December-February) diurnal warming amplitude in the CNRMOM1D/ GELATO ERA1h forced simulation. Contour interval is $0.05^{\circ} \mathrm{C}$.

time series allows an evaluation of the differences in SST variability between the two experiments on daily time scales and longer. In the rest of the paper, we will use the notation $\Delta \overline{\mathrm{SST}}$, defined in the introduction, for the time series of the difference between ERA1h and ERA24h daily mean temperature (ERA1h-ERA24h). The time mean of $\Delta \overline{\mathrm{SST}}$ is negligible as the mean state of ERA1h and ERA24h are constrained to be the same; $\Delta \overline{\mathrm{SST}}$ represents the correction in daily mean SST induced by the ocean diurnal variability. The first aim of this study is to quantify the amplitude and the persistence of this correction. We then investigate the factors responsible for this correction.

\section{b. Can any impact of the SST diurnal variations on the SST variability on longer time scales be detected?}

The standard deviation (std) of $\Delta \overline{\mathrm{SST}}[\operatorname{std}(\Delta \overline{\mathrm{SST}})]$ is a measure of the difference in SST amplitude that can be reached between the two experiments under the same daily mean forcing (Figs. 6a,b). This standard deviation is higher in summer (MJJAS) than in winter (NDJFM), as expected from the fact that the SST diurnal cycle is larger in summer that in winter. In the extratropics, $\operatorname{std}(\Delta \overline{\mathrm{SST}})$ ranges between $0.3^{\circ}$ and $0.5^{\circ} \mathrm{C}$ between $30^{\circ}$ and $60^{\circ} \mathrm{N}$ in summer while it is close to $0^{\circ} \mathrm{C}$ in winter. In the tropics, $\operatorname{std}(\Delta \overline{\mathrm{SST}})$ is about $0.5^{\circ} \mathrm{C}$ and can reach $2^{\circ} \mathrm{C}$ in the eastern part of the Atlantic Ocean. For a comparison, the standard deviation of the daily SST time series of ERA1h, which reflects the amplitude of the SST variability on daily time scales and longer, is around $1^{\circ} \mathrm{C}$ in the summer hemisphere and can reach $2^{\circ} \mathrm{C}$ in the eastern part of the tropical band (Figs. $6 \mathrm{c}, \mathrm{d}$ ). Thus, the differences between ERA1h and ERA24h daily SSTs under the same daily mean forcing represent about $30 \%-50 \%$ of the SST anomalies on daily time scales and longer. A subsequent key question is then as follows: are these differences only noise or are they consequences of physical processes involving the ocean diurnal variations? In the rest of this paper, we will focus on the 

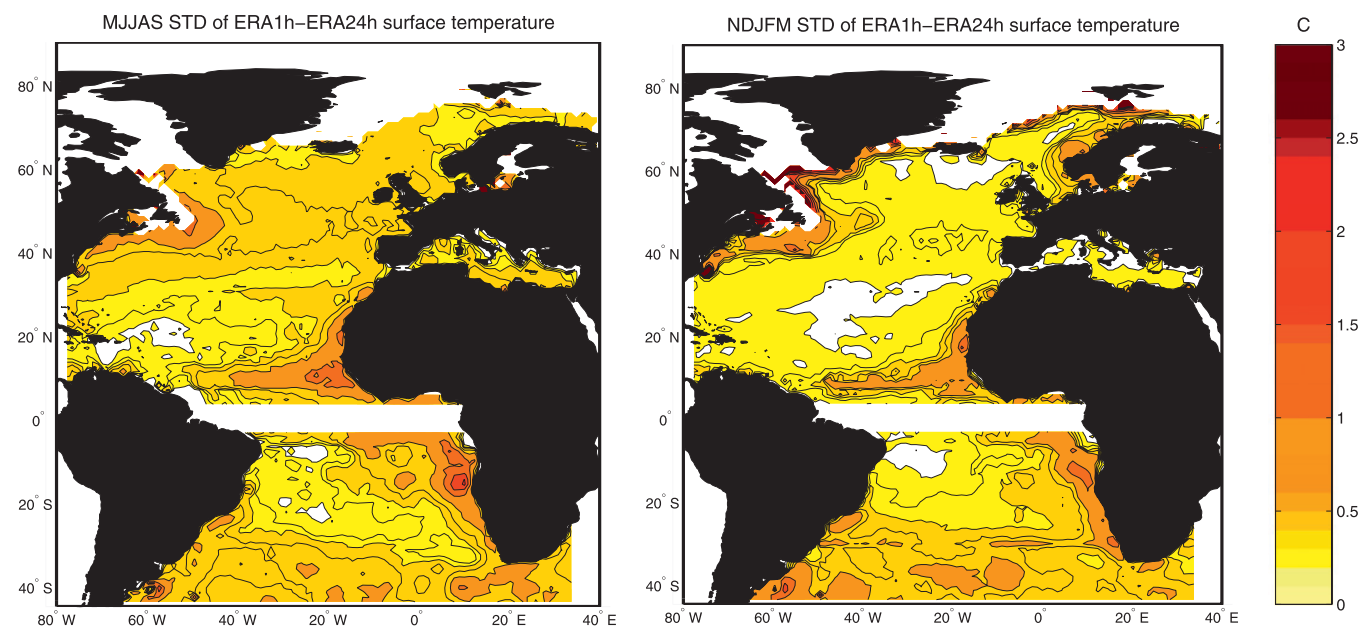

MJJAS STD of ERA1h daily surface temperature
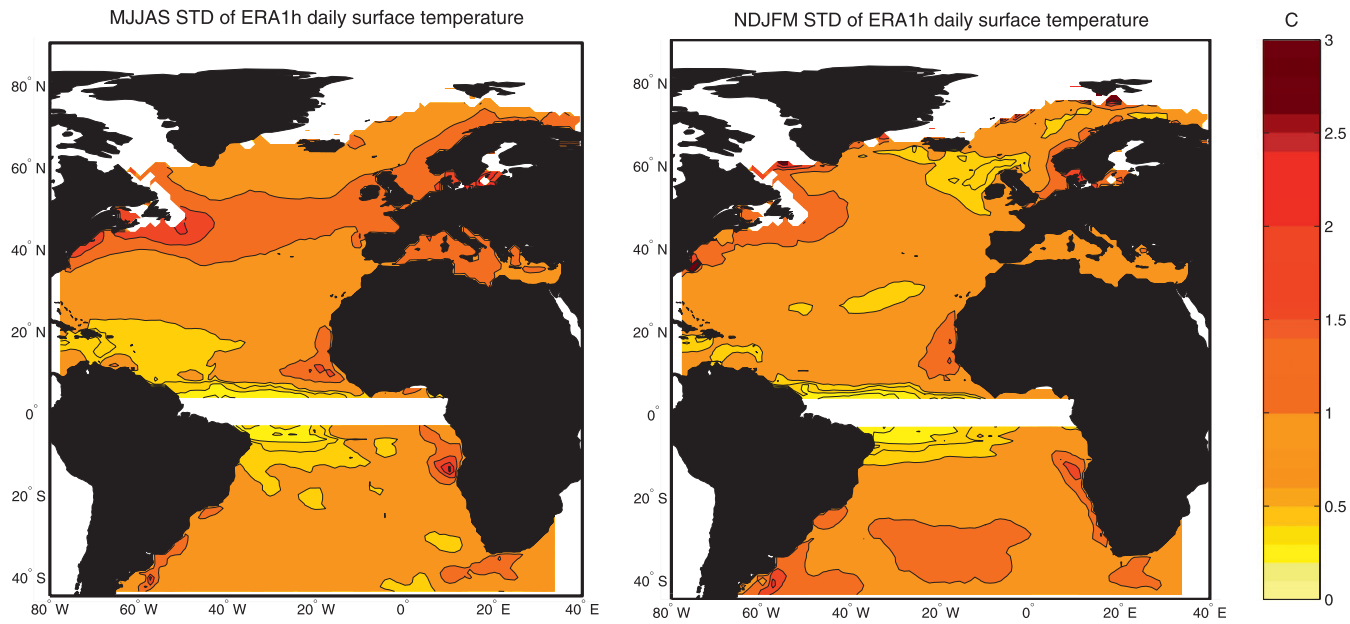

FIG. 6. Standard deviation of the (top) daily $\Delta \overline{\mathrm{SST}}$ (see details in the text) and (bottom) ERA1h SST time series for the (left) summer (May-September) and (right) winter (November-March) seasons. Contour interval is $0.1^{\circ} \mathrm{C}$ below $0.5^{\circ} \mathrm{C}$ and $0.5^{\circ} \mathrm{C}$ above.

summer hemisphere in the mid- to high latitudes and on the full year in the tropics because the impact of ocean diurnal cycle on daily SST is negligible during winter in mid- to high latitudes (Fig. 6).

The $\Delta \overline{\mathrm{SST}}$ time series is basinwide anticorrelated with the difference in daily mean mixed layer depth between ERA1h and ERA24h (Fig. 7). The colored correlations are significant to the $95 \%$ level, if using a Student test. This is consistent with the mean temperature profile in the ocean: the water below the mixed layer is cooler than in the mixed layer. Thus, a deepening of the mixed layer corresponds to the entrainment of cool water from below the mixed layer, which leads to a cooling of the sea surface. This result suggests that the difference in surface temperature between ERA1h and ERA24h is driven by nonlinear processes, which have an influence on the mixed layer depth. A potential culprit for these nonlinear processes could be the turbulent mixing. The significant positive correlations near the equator are not reliable as the CNRMOM1D does not explicitly resolve the upwellings there.

The decorrelation time of the $\Delta \overline{\mathrm{SST}}$ time series is computed as the time for which the lagged correlation of $\Delta \overline{\mathrm{SST}}$ decreases below the $95 \%$ level of significance using a Student test (Fig. 8). This decorrelation time reflects the persistence of the correction in daily mean temperature due to the representation of the ocean diurnal variations, that is, the mean time during which a correction of the same sign is significant. The persistence of this correction ranges from 15 to 40 days in the midlatitudes and exceeds 60 days in the tropics. At this point, we cannot know the origin of this persistence. It can be mediated via oceanic processes or via atmospheric persistence. However, even if the persistence of the correction is mediated by an atmosphere persistence, taking the ocean diurnal variations into account 


\section{MJJAS (ERA1h-ERA24h MLD) vs $\triangle \overline{S S T}$}

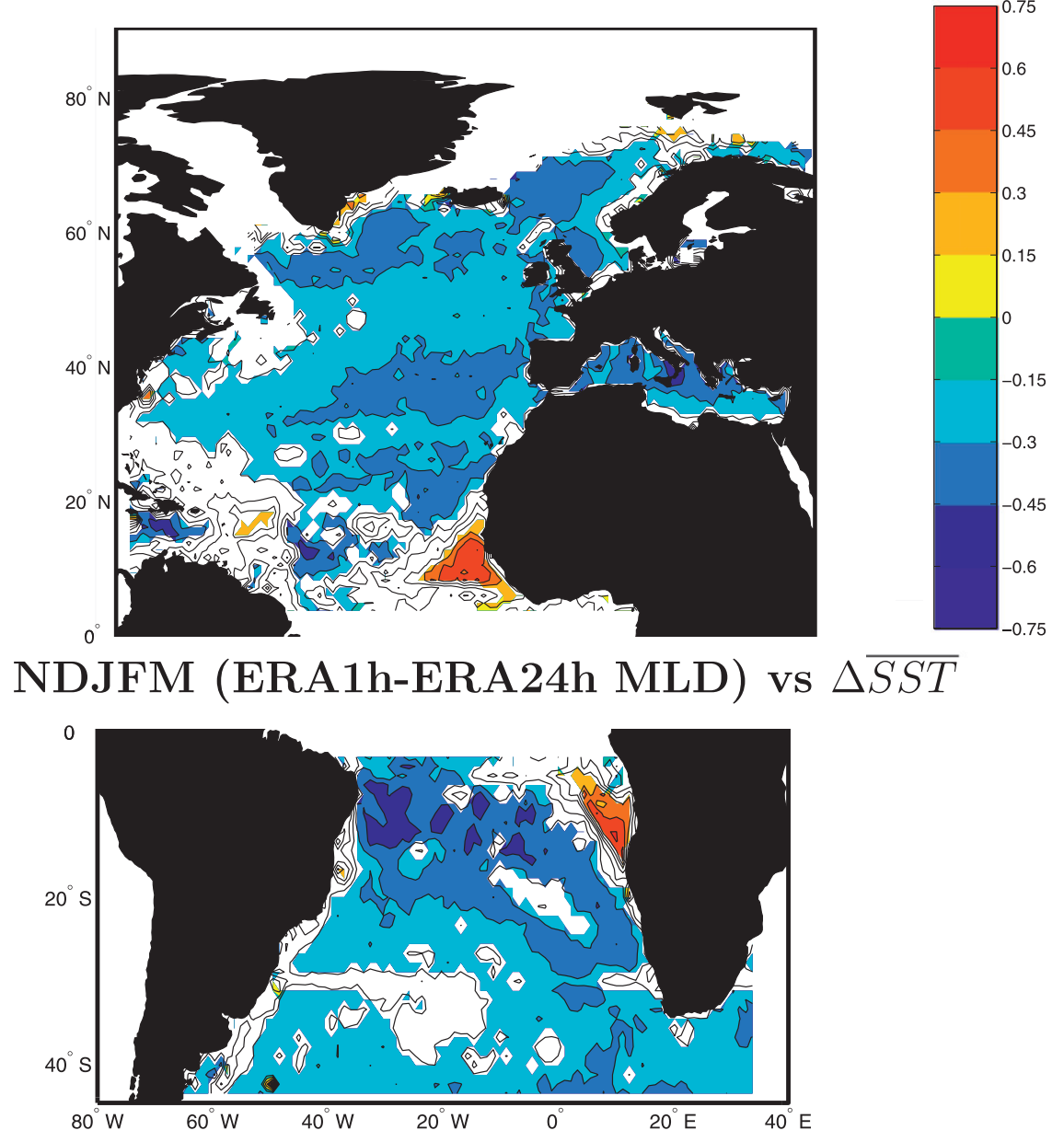

FIG. 7. Correlations between the $\Delta \overline{\text { SST }}$ time series (difference in daily mean SST) and the time series of the difference in daily mean mixed layer depth between ERA1h and ERA24h. Only the correlations significant to the $95 \%$ level, according to a $t$ test, are drawn. Contour interval is 0.15 .

leads to a correction in daily mean SST that has the same sign for at least 15 days. This effect is illustrated in Fig. 9. We can see in this schematic the correlation between the daily variability in ERA1h and ERA24h as they are forced by the same atmospheric data. We can also see that the persistence of the $\Delta \overline{\mathrm{SST}}$ correction in daily mean SST by more than 15 days implies that the ocean diurnal variability is able to affect the intraseasonal SST variability.

In this section, we have shown that taking the ocean diurnal variations into account can lead to a typical correction of about $0.3^{\circ}-0.5^{\circ} \mathrm{C}$ in daily mean temperature in the midlatitudes in summer and of about $0.5^{\circ}-1^{\circ} \mathrm{C}$ in the tropics year-round. Furthermore, as this correction can persist from 15 to 40 days in the midlatitudes and more than 60 days in the tropics, the intraseasonal SST variability can be affected by the representation of the ocean diurnal variations. In the rest of this paper, we will focus on the causes of this daily mean correction, and we will let aside the origin of the persistence of this correction. Our goal is to investigate how taking the daily peak in SST and diurnal mixed layer depth variations into account can affect the daily mean SST.

\section{c. Impact of the ocean diurnal variations in the tropics}

In the introduction, we have presented the results from Bernie et al. (2005) and Shinoda (2005) who showed that taking into account the ocean diurnal cycle enhances the intraseasonal variability by about $20 \%$. They found that a positive $\Delta \overline{\mathrm{SST}}$ systematically occurs together with a positive temperature anomaly relative to the seasonal mean. Here, we compute the correlation 

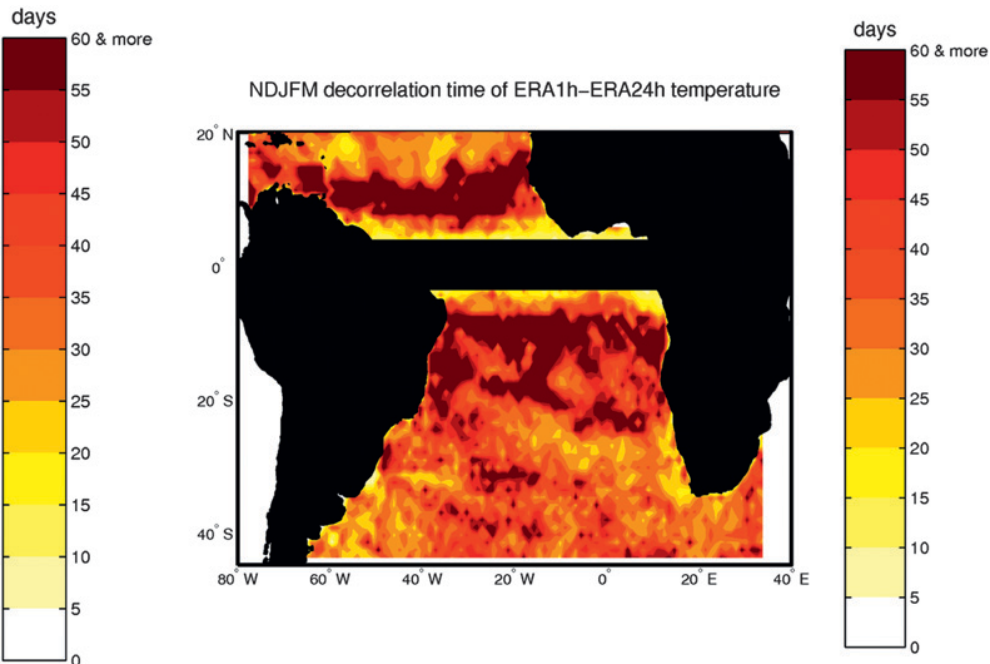

FIG. 8. Decorrelation time of the time series of the difference in daily SST between ERA1h and ERA24h $(\Delta \overline{\mathrm{SST}})$. Contour interval is 5 days.

between $\Delta \overline{\mathrm{SST}}$ and the ERA1h anomalies in daily mean surface temperature for each grid point (Fig. 10) to examine if the same result is found in our simulation. This correlation ranges between 0.5 and 0.9 in the tropical band and between 0.2 and 0.5 in the southern Atlantic in austral summer, but is not significant in the northern Atlantic in boreal summer. In agreement with the results from Shinoda (2005) and Bernie et al. (2005), we find that if we only consider days in which diurnal warming is larger than its seasonal mean, these systematically correspond to a positive correction in daily mean SSTs in the tropics, while they correspond to positive or negative corrections in the midlatitudes. We conclude that the rectification mechanism of Bernie et al. (2005) and Shinoda (2005) is adapted to explain the role of the ocean diurnal cycle on the intraseasonal SST variability in the tropics but not in the midlatitudes.

Shinoda's (2005) rectification mechanism relies on the hypothesis that the turbulent mixing is strong enough during the night to clear the mixed layer memory or that the mixed layer is shallow enough during the day so that the stratification is easily eroded during the following night. Under this hypothesis, the simulated temperature profiles should be the same in ERA1h and ERA24h during the night. However, in ERA24h, a constant daily mean solar heat flux is applied through the day while in ERA1h; the solar heat flux equals 0 during the night. So we can expect differences in the night temperature profile between ERA1h and ERA24h. These differences are negligible in the tropics but not in the midlatitudes (not shown). This explains why the rectification mechanism is not adapted in the midlatitudes. The aim of the next section is to investigate the physical processes explaining how the ocean diurnal variations induce a daily mean SST correction in the midlatitudes.

\section{d. Impact of the ocean diurnal variations in the midlatitudes}

From Fig. 7, we deduced that nonlinear processes probably associated with the turbulent mixing can make the mean mixed layer depth shallower and the sea surface temperature warmer in ERA1h or in ERA24h under the same daily mean forcing. These nonlinear processes may be linked with the diurnal variations in surface turbulent fluxes. In this section, we examine the role of diurnal variations of the wind stress and nonsolar heat flux on the daily mean SST. Each day is divided into 4 periods of $T_{i}=6 \mathrm{~h}: d_{0}=[0-6 \mathrm{~h}], d_{1}=[6-12 \mathrm{~h}], d_{2}=$ [12-18 h], and $d_{3}=[18-24 \mathrm{~h}]$. We first compute, $\tau(d, i)$ and $Q_{\mathrm{NS}}(d, i)$, the 6-hourly averages of the wind stress and nonsolar heat flux, respectively, for each period

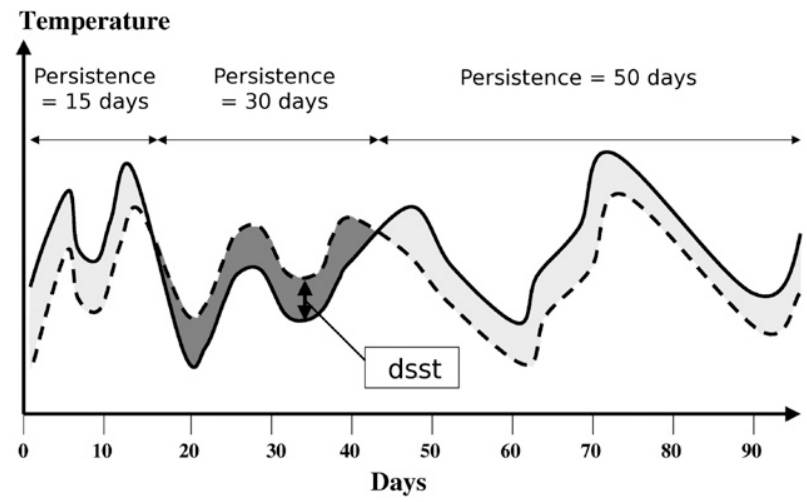

FIG. 9. Schematic illustrating the impact of $\Delta \overline{\mathrm{SST}}$ mean persistence. 

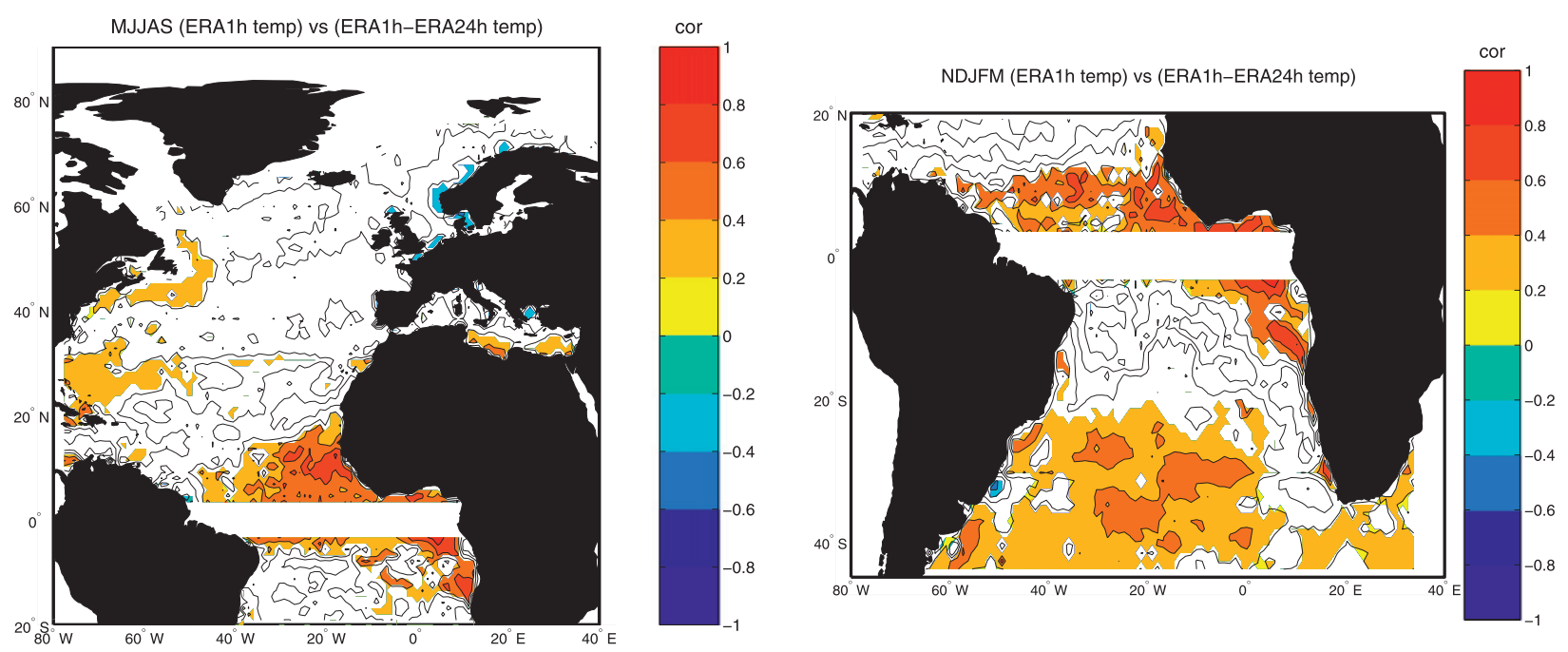

FIG. 10. Correlations between the $\Delta \overline{\mathrm{SST}}$ time series (difference in daily mean SST) and the time series of daily mean SSTs in ERA1h. Only the correlations significant to the $95 \%$ level, according to a $t$ test, are drawn. Contour interval is 0.2 .

$i=0,3$ of each day $d$. We then define $\Delta Q_{\mathrm{NS}}(d, i)$ and $\Delta \tau(d, i)$ that represent the diurnal anomalies in wind stress and non solar heat flux relative to their daily mean:

$$
\begin{gathered}
\Delta Q_{\mathrm{NS}}(d, i)=Q_{\mathrm{NS}}(d, i)-\frac{1}{4} \sum_{i=0}^{i=3} Q_{\mathrm{NS}}(d, i), \quad \text { and } \\
\Delta \tau(d, i)=\tau(d, i)-\frac{1}{4} \sum_{i=0}^{i=3} \tau(d, i) .
\end{gathered}
$$

The effect of wind stress on the turbulent mixing is highly nonlinear. Indeed, a variation in wind stress can be more effective on the sea surface temperature when the wind stress is small than when it is large. For example, for a day of large solar heat flux, when the wind stress is large, the density profile is mixed up over a deep layer. In this case, if the wind stress increases, it will cause a deepening of the mixed layer and entrainment of waters from below the mixed layer, which are slightly colder than the mixed layer. When the wind stress is weak, the mixed layer is shallow and the density profile is very stable, with a high temperature gradient. In this case, if the wind stress increases, it will cause entrainment of waters from below the mixed layer, which are much colder than the mixed layer. To account for this role of weak wind stress on SST, we define $\Delta \% \tau$ :

$$
\Delta \% \tau\left(d_{i}\right)=\frac{\Delta \tau\left(d_{i}\right)}{\frac{1}{4} \sum_{i=0}^{i=3} \tau\left(d_{i}\right)} .
$$

While $\Delta Q_{\mathrm{NS}}$ corresponds to the difference in nonsolar heat flux between ERA1h and ERA24h, $\Delta \% \tau$ corresponds to the relative anomaly in wind stress between ERA1h and ERA24h.

At each horizontal grid point, lagged composites of $\Delta Q_{\text {NS }}$ in summer (MJJAS) over the North Atlantic Ocean are computed for the days that $\Delta \overline{\mathrm{SST}}$ is higher than one standard deviation of the $\Delta \overline{\mathrm{SST}}$ time series. This gives a time series of 6-hourly composite anomalies in nonsolar heat flux between ERA1h and ERA24h, from 5 days before until 5 days after the day that $\Delta \overline{\mathrm{SST}}>\operatorname{std}(\Delta \overline{\mathrm{SST}})$ at each grid point. The significance level of the composites is assessed using a classical bootstrap test: we draw a distribution of $\Delta \overline{\mathrm{SST}}$ mean anomaly over the same number of days as selected for the composite, and the $\Delta \overline{\mathrm{SST}}$ mean anomaly obtained in the composite is compared to this distribution. The domain where $\Delta Q_{\mathrm{NS}}$ is significant at the $95 \%$ level covers a spatial extent that increases until the 18-24-h time interval at day -1 and then decreases. This spatial extent is shown in Fig. 11a. We use it as a mask to average the composite time series of 6-hourly $\Delta Q_{\mathrm{NS}}$, and we obtain the mean time series shown in Fig. 11b. For readability, the mean composite time series of 0-6- and 6-12-h $\Delta Q_{\mathrm{NS}}$ are also shown in Fig. 11c while the mean composite time series of 12-18- and 18-24-h $\Delta Q_{\mathrm{NS}}$ are shown in Fig. 11d. The horizontal dashed lines correspond to the seasonal means of 0-6- and 6-12-h $\Delta Q_{\mathrm{NS}}$ in Fig. $11 \mathrm{c}$ and the seasonal means of $12-18-$ and $18-24-\mathrm{h}$ $\Delta Q_{\mathrm{NS}}$ in Fig. 11d.

From the spatial averaged time series of $\Delta Q_{\text {NS }}$ (Fig. 11), we can conclude that a higher temperature in ERA1h than ERA24h is significantly linked to strong diurnal variations of the nonsolar heat flux the day before. These diurnal variations consist of a negative anomaly in $\Delta Q_{\mathrm{NS}}$ 
a) Mask

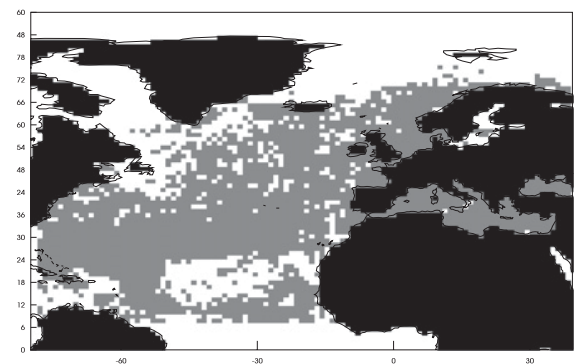

c) $\Delta Q_{N S}(0-6 h)$ and $\Delta Q_{N S}(6-12 h)$

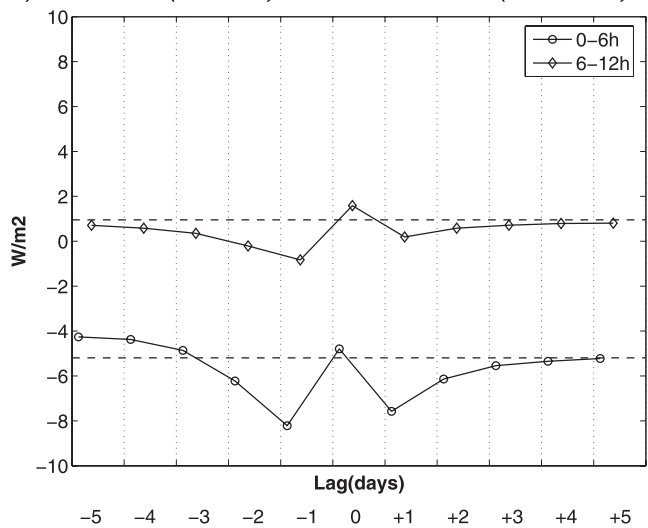

b) $\Delta Q_{N S}$

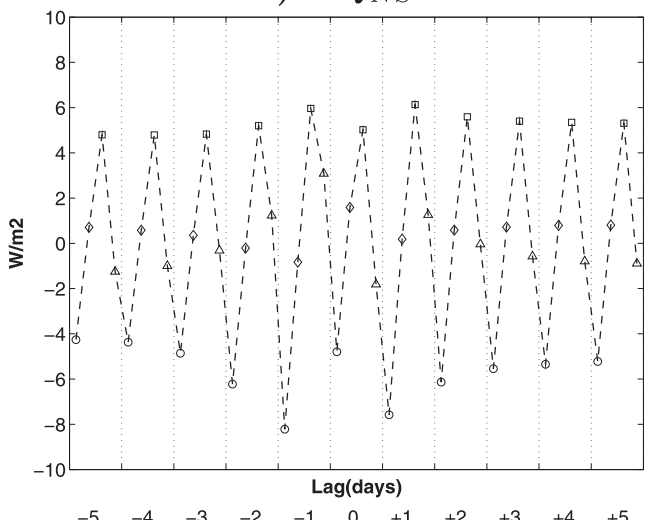

d) $\Delta Q_{N S}(12-18 h)$ and $\Delta Q_{N S}(18-24 h)$

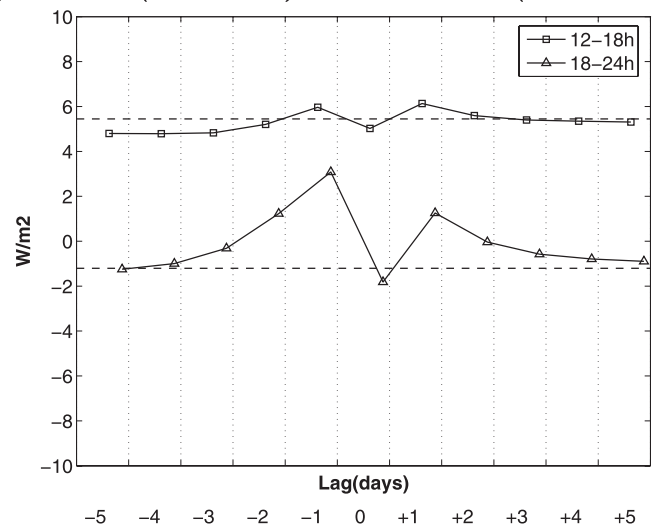

FIG. 11. (a) Mask: In gray, area where the composites of $\Delta Q_{\mathrm{NS}}$, selecting the days for which $\Delta \overline{\mathrm{SST}}>\operatorname{std}(\Delta \overline{\mathrm{SST}})$, reach the $95 \%$ significance level at day -1 , according to a bootstrap test. The $\Delta Q_{\mathrm{NS}}$ and $\Delta \overline{\mathrm{SST}}$ are defined in the text. (b) Spatial average over the mask in (a) of these composites of $\Delta Q_{\text {NS. }}$ (c) Time series of the 0-6- and 6-12-h values from (a) with their seasonal mean (dotted line). (d) Time series of the 12-18- and 18-24-h values from (a) with their seasonal mean (dotted line). Day 0 is a day for which $\Delta \overline{\mathrm{SST}}$ is higher than its standard deviation.

during the first half of the day and a positive one during the second half. According to our convention, this corresponds to a nonsolar heat flux toward the atmosphere that is larger than usual during the first half of the day and weaker than usual during the second half. The stronger anomalies occur during the 0-6- and 18-24-h time intervals. Opposite anomalies of smaller amplitude occur at day 0 . The same composites selecting the days that $\Delta \overline{\mathrm{SST}}$ is lower than $-\operatorname{std}(\Delta \overline{\mathrm{SST}})$ give symmetrical results but with a weaker amplitude in nonsolar heat flux anomaly.

Lagged composites of $\Delta \% \tau$ in summer (MJJAS) over the North Atlantic Ocean were also computed at each grid point, with the same selection criterion of $\Delta \overline{\mathrm{SST}}>$ $\operatorname{std}(\Delta \overline{\mathrm{SST}})$, from 5 days before to 5 days after the selected days. The spatial extent of the domain where $\Delta \% \tau$ is significant at the $95 \%$ level increases until the $0-6$-h time interval at day -1 and then decreases. This maximum spatial extent is shown in Fig. 12a. The average over this mask of the 6-hourly $\Delta \% \tau$ composites is shown in Fig. 12b. As for Fig. 11, the mean composite time series of $0-6$ - and 6-12-h $\Delta \% \tau$ along with their associated seasonal means are also shown in Fig. 12c, while those of 12-18- and 18-24-h $\Delta \% \tau$ are shown in Fig. 12d.

Figure 12 shows that a higher temperature in ERA1h than ERA24h at day 0 is significantly linked to strong diurnal variations of the wind stress at day -1 . These consist of a positive anomaly in $\Delta \% \tau$ during the first half of the day and a negative one during the second half. The strongest anomalies occur during the 0-6- and 1824-h time intervals. During day 0, a positive anomaly in wind stress occurs at the beginning and at the end of the day (0-6 and 18-24 h) while a negative one occurs during the 6-18-h time interval. The same composites selecting the days that $\Delta \overline{\mathrm{SST}}$ is lower than $-\operatorname{std}(\Delta \overline{\mathrm{SST}})$ gives symmetrical results but with a weaker amplitude in wind stress relative anomaly.

The same analyses applied to the South Atlantic Ocean during austral summer (NDJFM) give the same qualitative 
a) Mask

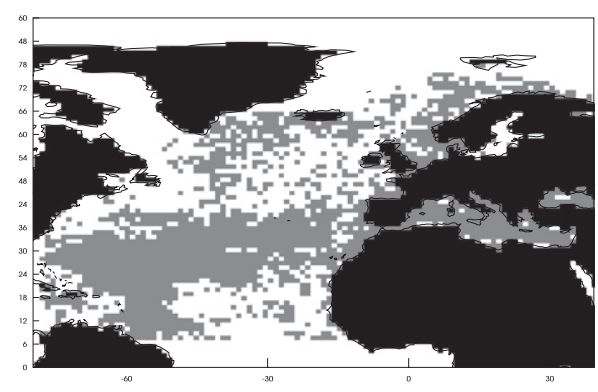

c) $\Delta \% \tau(0-6 h)$ and $\Delta \% \tau(6-12 h)$

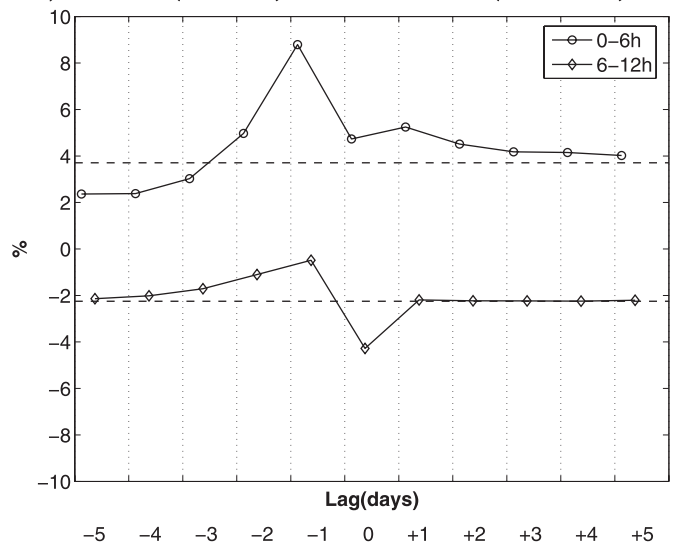

b) $\Delta \% \tau$

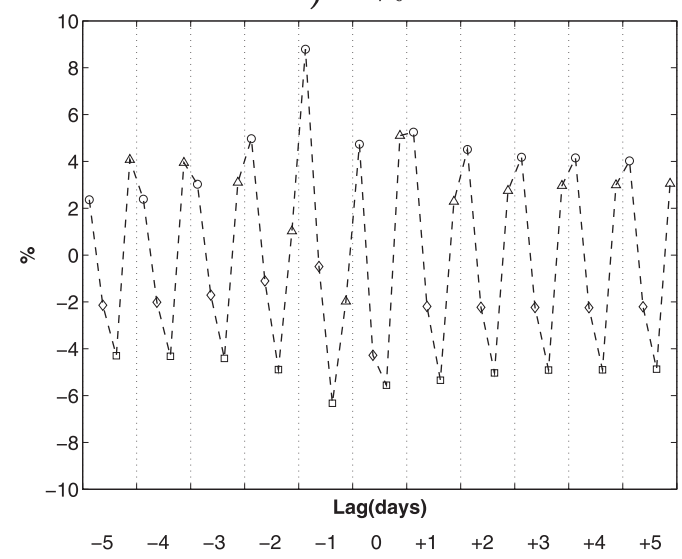

d) $\Delta \% \tau(12-18 h)$ and $\Delta \% \tau(18-24 h)$

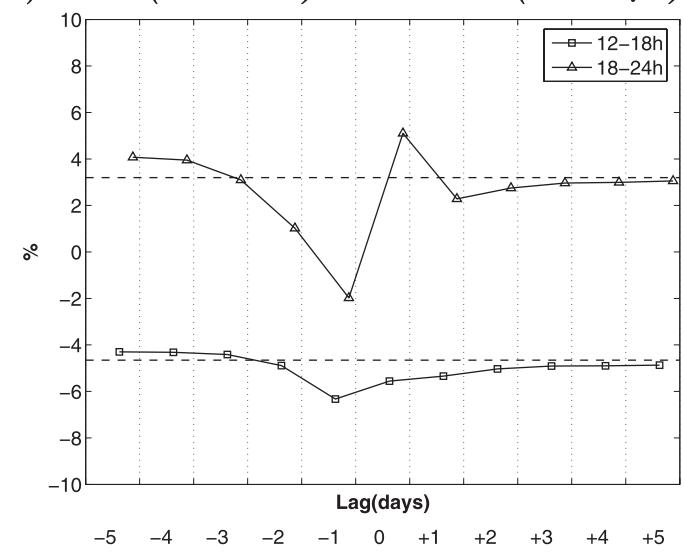

FIG. 12. (a) Mask: In gray, area where the composites of $\Delta \% \tau$, selecting the days for which $\Delta \overline{\mathrm{SST}}>\operatorname{std}(\Delta \overline{\mathrm{SST}})$, reach the $95 \%$ significance level at day -1 , according to a bootstrap test. The $\Delta \% \tau$ and $\Delta \overline{\mathrm{SST}}$ are defined in the text. (b) Spatial average over the mask in (a) of these composites of $\Delta \% \tau$. (c) Time series of the 0-6- and 6-12-h values from (a) with their seasonal mean (dotted line). (d) Time series of the 12-18- and 18-24-h values from (a) with their seasonal mean (dotted line). Day 0 is a day for which $\Delta \overline{\mathrm{SST}}$ is higher than its standard deviation.

results for both the wind stress and the nonsolar heat flux. These composites suggest that a higher daily temperature in ERA1h than ERA24h is associated with stronger than usual diurnal variations in wind stress and nonsolar heat flux, reaching a maximum anomaly of $8 \%-10 \%$ and $\pm 5 \mathrm{~W} \mathrm{~m}^{-2}$, respectively. This relationship concerns most of the midlatitude Atlantic Ocean, as shown in Figs. 11 and 12 for the North Atlantic Ocean. However, the amplitudes of the anomalies shown in Figs. 11 and 12 are small, though significant to the $95 \%$ level. These anomalies correspond to a spatial average of time composites. This averaging process tends to smooth the anomalies out. Diurnal anomalies in wind stress or nonsolar heat flux relative to their daily mean can reach an amplitude of about $0.05 \mathrm{~N} \mathrm{~m}^{-2}$ or $50 \mathrm{~W} \mathrm{~m}^{-2}$ in the midlatitudes (computed by the model via ECUME bulk formulae). Some examples of wind stress and nonsolar heat flux time series selected from the first boreal summer of ERA1h simulation and showing such sharp variations during the course of the day are gathered in appendix A. From now on, we will not focus on the atmospheric causes for these wind stress and nonsolar heat flux anomalies but only on the processes by which these diurnal anomalies affect the daily mean SST.

\section{Idealized experiments: How can diurnal variations in wind stress and non solar heat flux affect the daily mean SST?}

a. Forcing the ocean model with diurnal variations in wind stress and nonsolar heat flux obtained by composites

To test the physical relevance of the statistical link between diurnal variations in surface turbulent fluxes and correction in daily mean SST, and to explain by which 
a) Solar heat flux

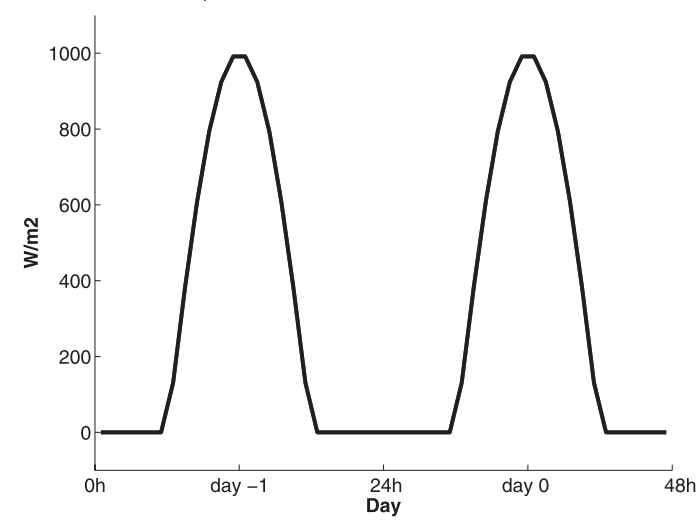

b) Zonal wind stress

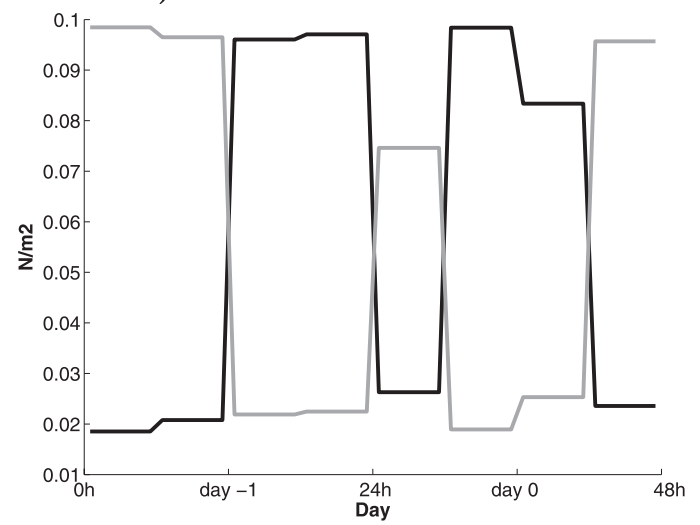

d) SST

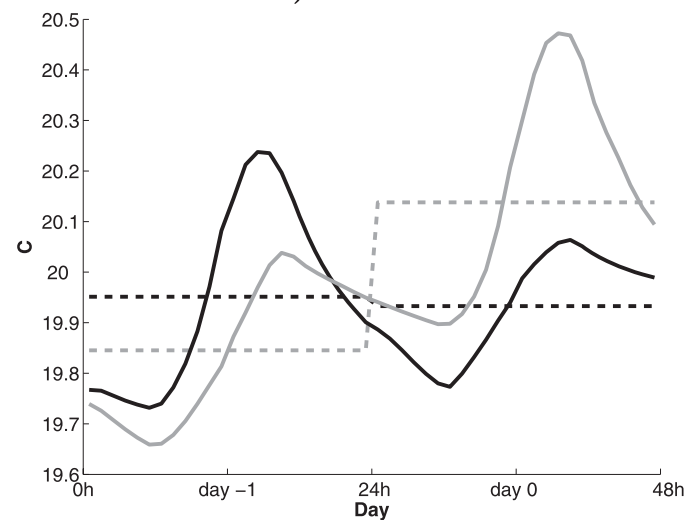

c) Non solar heat flux

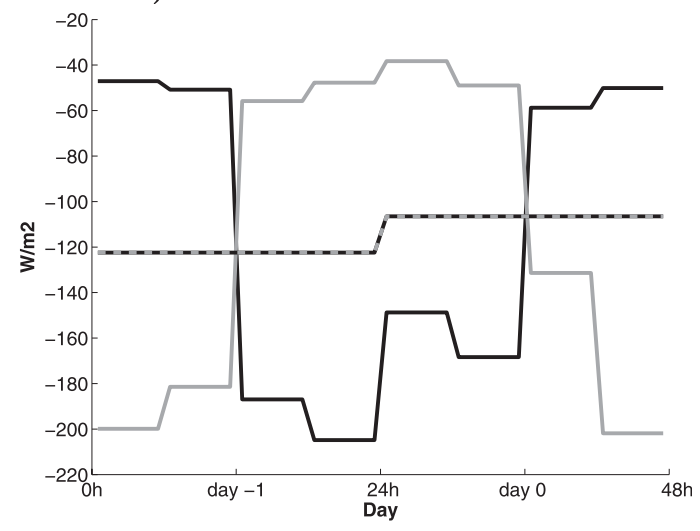

e) Temperature profiles $24 h$

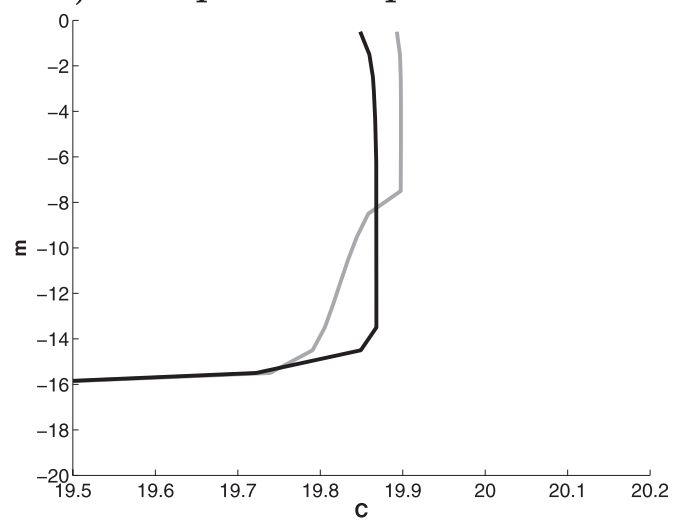

FIG. 13. (a) Solar heat flux applied in both experiments in $\mathrm{W} \mathrm{m}^{-2}$. Outputs of the idealized experiments $T_{\text {tot }}^{+}$, in gray and $T_{\text {tot }}^{-}$, in black, described in appendix B: (b) Zonal wind stress in $\mathrm{N} \mathrm{m}^{-2}$; (c) nonsolar heat flux in $\mathrm{W} \mathrm{m}^{-2}$, and daily mean nonsolar heat flux as dashed lines; d) sea surface temperatures in ${ }^{\circ} \mathrm{C}$ and daily mean SST as dashed lines; and (e) temperature profiles at the end of day -1. A positive heat flux corresponds to an input of heat in the ocean.

mechanism this link operates, ocean forced experiments under idealized forcings are conducted in the next sections. In these experiments, an ocean column represented by CNRMOM1d is run for two days under idealized forcings with diurnal variations typical of the day -1 and day 0 nonsolar heat flux and wind stress variations found by compositing in previous section (Figs. 11 and 12). We focus on the impact of these forcings during day 0 .

Two experiments $T_{\text {tot }}^{+}$and $T_{\text {tot }}^{-}$are defined. The details about their design are given in appendix B. The time series of solar heat flux applied in both experiments is shown in Fig. 13a. Its peak value is $1000 \mathrm{~W} \mathrm{~m}^{-2}$ for both 
days. The time series of wind stress in the $T_{\text {tot }}^{+}$experiment (Fig. 13b) corresponds to an enhanced wind stress during the first half of day -1 and a reduced one during the second half of that day. For day 0 , the wind stress is enhanced at the beginning and at the end of the day while it is reduced in the 6-18-h interval. This forcing corresponds to the typical anomalies computed for days when a higher temperature is obtained in ERA1h than ERA24h, as shown by Fig. 12. The time series of the nonsolar heat flux in the $T_{\text {tot }}^{+}$experiment (Fig. 13c) corresponds to an enhanced heat loss during the first half of day -1 and a reduced one during the second half of that day and the opposite for day 0 . This forcing corresponds to the anomalies associated with a higher temperature in ERA1h than ERA24h (Fig. 11). The time series of wind stress and nonsolar heat flux in the $T_{\text {tot }}^{-}$experiment corresponds to opposite anomalies relative to their daily mean. Thus, the daily mean temperature is expected to be higher at day 0 in $T_{\text {tot }}^{+}$than in $T_{\text {tot }}^{-}$experiment.

Indeed, Fig. 13d shows that the daily mean SST is higher by $0.21^{\circ} \mathrm{C}$ at day 0 in $T_{\text {tot }}^{+}$than in $T_{\text {tot }}^{-}$experiment. Since the net surface heat flux drives the SST trend, the evolution of the SST is delayed compared to the evolution of the net surface heat flux. At day -1 , the nonsolar heat flux in the $T_{\text {tot }}^{+}\left(T_{\text {tot }}^{-}\right)$experiment corresponds to a heat loss anomaly for (an input of heat anomaly in) the ocean during the first half of the day and an input of heat anomaly (heat loss anomaly) during the second half of the day. Without any other effect, this would tend to decrease (increase) the SST during the first half of the day and increase (decrease) it during the second half in $T_{\text {tot }}^{+}\left(T_{\text {tot }}^{-}\right)$. The SST at the end of day -1 would be the same in $T_{\text {tot }}^{+}$and $T_{\text {tot }}^{-}$experiments since at this point the same amount of heat has been received by the ocean in both experiments. However, since the SST would be higher all along the day in $T_{\text {tot }}^{-}$than in $T_{\text {tot }}^{+}$, its daily mean SST would also be higher. With opposite anomalies in nonsolar heat flux at day 0 , we would obtain a higher daily mean SST at day 0 in $T_{\text {tot }}^{+}$than in $T_{\text {tot }}^{-}$and the difference in daily mean SST between $T_{\text {tot }}^{+}$and $T_{\text {tot }}^{-}$ would be equal in magnitude and opposite to the one at day -1 . However, the difference in daily mean SST between $T_{\text {tot }}^{+}$and $T_{\text {tot }}^{-}$is higher at day 0 than at day -1 (Fig. 13d). The effect of the delay in the SST evolution with respect to the nonsolar heat flux evolution can partly explain the higher daily mean SST at day 0 in $T_{\text {tot }}^{+}$ than in $T_{\text {tot }}^{-}$experiment (Fig. 13d), but this is not sufficient to explain the total difference.

Furthermore, we can see that the SST at the end of day -1 is higher by $0.05^{\circ} \mathrm{C}$ in $T_{\text {tot }}^{+}$than in $T_{\text {tot }}^{-}$experiment. This difference in SST is associated with the differences in temperature profiles at the end of day -1 shown on Fig. 13e. The differences in density profiles (not shown) are mainly due to differences in temperature profiles. This temperature profile is more stable and the mixed layer is shallower in $T_{\text {tot }}^{+}$than in $T_{\text {tot }}^{-}$. With a shallower mixed layer at the beginning of day 0 , more heat is trapped near the surface in $T_{\text {tot }}^{+}$than in $T_{\text {tot }}^{-}$. This partly explains the higher daily mean SST during day 0 in $T_{\text {tot }}^{+}$than in $T_{\text {tot }}^{-}$.

To further analyze the mechanism by which diurnal variations in wind stress and nonsolar heat flux affects the daily mean SST, we perform two other sets of experiments, focusing on the role of the nonsolar heat flux on the one hand and the role of wind stress on the other.

\section{b. Sensitivity to diurnal variations in non solar heat fluxes}

The first set of complementary experiments consists of $T_{Q}^{+}$and $T_{Q}^{-}$defined as follows. The time series of nonsolar heat flux and freshwater fluxes computed by CNRMOM1D in the $T_{\text {tot }}^{+}$and $T_{\text {tot }}^{-}$experiments are used to force CNRMOM1D in the $T_{Q}^{+}$and $T_{Q}^{-}$, respectively. The time series of wind stress forcing in $T_{Q}^{+}$and $T_{Q}^{-}$are taken as the daily mean values of $T_{\text {tot }}^{+}$and $T_{\text {tot }}^{-}$, respectively. These sensitivity experiments therefore allow us to investigate the impact of diurnal variations in nonsolar heat flux on the daily mean SST at day 0, independently of the effects of diurnal variations in wind stress. The time series of SST during day -1 and day 0 are shown in Fig. 14a, and the temperature profiles at the end of day -1 are shown in Fig. 14b in gray and black for $T_{Q}^{+}$and $T_{Q}^{-}$, respectively.

At day 0 , we obtain a higher daily mean SST in $T_{Q}^{+}$ than in $T_{Q}^{-}$, by $0.07^{\circ} \mathrm{C}$. This difference only amounts to $33 \%$ of the difference between $T_{\text {tot }}^{+}$and $T_{\text {tot }}^{-}$. As for the $T_{\text {tot }}^{+}$and $T_{\text {tot }}^{-}$experiments, the daily mean SST is higher in $T_{Q}^{-}$than in $T_{Q}^{+}$during day -1 because of the delayed effect of nonsolar heat flux differences on the SST. The anomalies in nonsolar heat flux relative to their daily mean have opposite signs in day 0 and day -1 . Thus, the delayed effect of nonsolar heat flux contributes to a higher daily mean SST in $T_{Q}^{+}$than in $T_{Q}^{-}$during day 0 . Furthermore, at the end of day -1 the SST is also higher (Fig. 14a) and the temperature profile more stable (Fig. 14b) in $T_{Q}^{+}$than in $T_{Q}^{-}$. The preconditioning of a shallower mixed layer depth in $T_{Q}^{+}$compared to $T_{Q}^{-}$ at the beginning of day 0 is due to the phasing of the imposed diurnal variations in nonsolar heat flux relative to the mixed layer diurnal cycle: in $T_{Q}^{+}$compared to $T_{Q}^{-}$, more (less) heat is extracted during the first (second) half of the day when the mixed layer is deeper (shallower). The extraction of heat from a shallow mixed layer is more efficient in cooling it down and deepening it than the extraction of heat from a deep mixed layer. During day 0 , this day -1 preconditioning of a shallower 
a) $T_{Q} \mathrm{SST}$

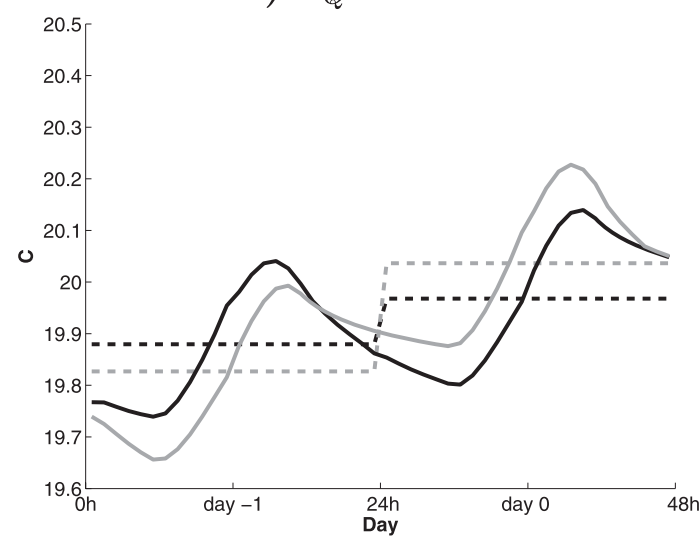

c) $T_{\tau} \mathbf{S S T}$

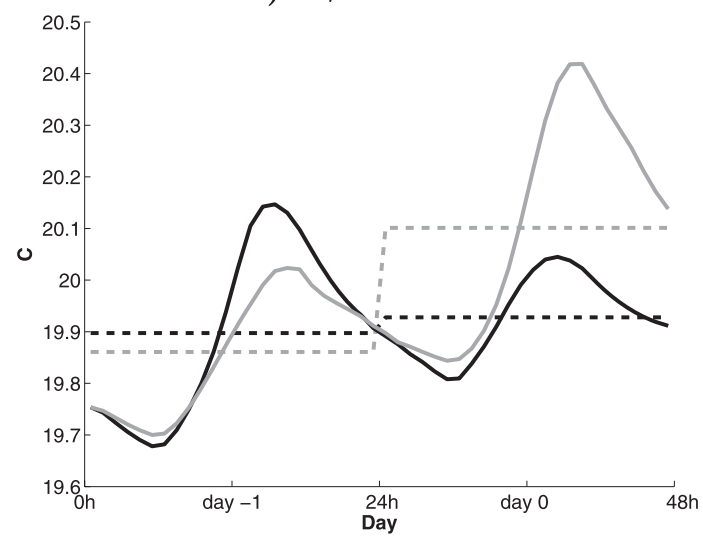

b) $T_{Q}$ Temperature profiles $24 h$

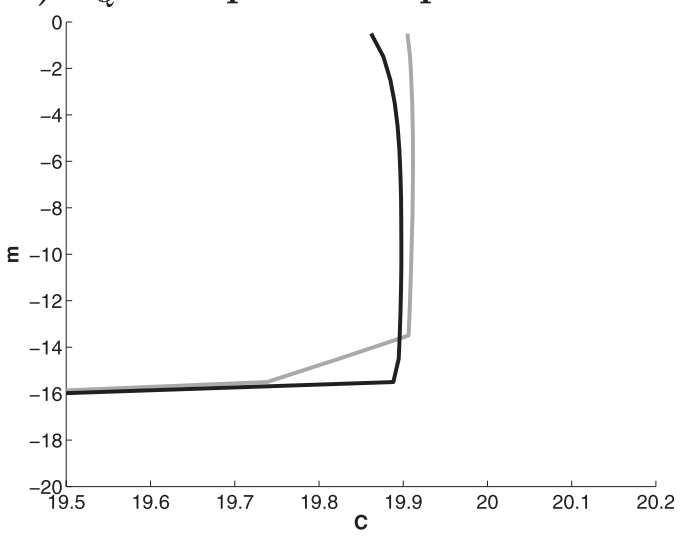

d) $T_{\tau}$ Temperature profiles $28 \mathrm{~h}$

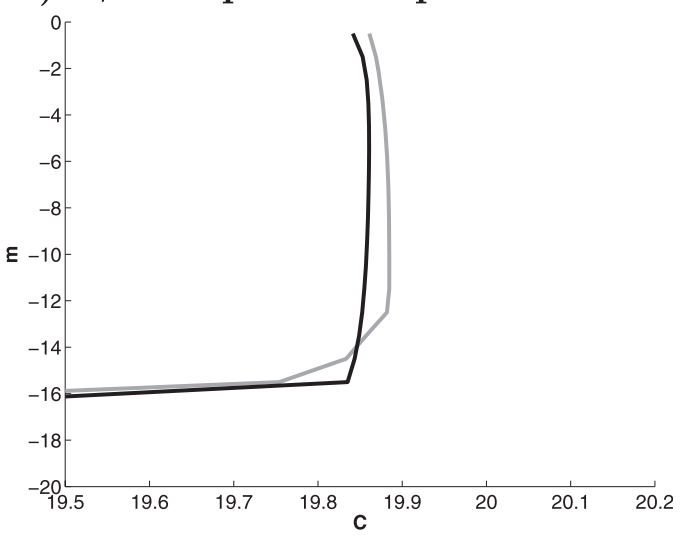

FIG. 14. Outputs of the idealized experiments $T_{Q}^{+}$(in gray) and $T_{Q}^{-}$(in black), described in section 4b: (a) Sea surface temperatures in ${ }^{\circ} \mathrm{C}$, and (b) temperature profiles at the beginning of day 0 in ${ }^{\circ} \mathrm{C}$. Outputs of the idealized experiments $T_{\tau}^{+}$(in gray) and $T_{\tau}^{-}$(in black), described in section $4 \mathrm{c}$ : (c) Sea surface temperatures in ${ }^{\circ} \mathrm{C}$, and (d) temperature profiles at the beginning of day 0 in ${ }^{\circ} \mathrm{C}$.

mixed layer allows more heat to be trapped near the surface and a higher daily mean SST in $T_{Q}^{+}$than in $T_{Q}^{-}$. Hence, two effects lead to a higher daily mean SST in $T_{Q}^{+}$ than in $T_{Q}^{-}$at day 0: the delayed effect of nonsolar heat flux on the SST and the preconditioning of the temperature profile during day -1 . However, it is hard to quantify the contribution of these two factors. The nonsolar heat flux is about $-165 \mathrm{~W} \mathrm{~m}^{-2}$ in $T_{O}^{-}$during the first half of day 0 while it is about $-190 \mathrm{~W} \mathrm{~m}^{-2}$ in $T_{Q}^{+}$ during the first half of day -1 (Fig. 13c). Consequently, the delayed effect of nonsolar heat flux must lead to a smaller difference in SST during day 0 than the $0.05^{\circ} \mathrm{C}$ obtained during day -1 .

Additional experiments have been run, changing the amplitude of the diurnal variations in nonsolar heat flux around their daily mean value. These experiments lead to similar qualitative conclusions. The stronger the diurnal variations, the higher the difference in daily mean SST is at day 0 between $T_{Q}^{+}$and $T_{Q}^{-}$.

\section{c. Sensitivity to diurnal variations in wind stress}

The second set of complementary experiments consists of $T_{\tau}^{+}$and $T_{\tau}^{-}$, defined as follows. The time series of wind stress and freshwater fluxes computed by CNRMOM1D in the $T_{\text {tot }}^{+}$and $T_{\text {tot }}^{-}$experiments are used to force CNRMOM1D in $T_{\tau}^{+}$and $T_{\tau}^{-}$, respectively. The time series of nonsolar heat flux forcing in $T_{\tau}^{+}$and $T_{\tau}^{-}$ are taken as the daily mean values of $T_{\text {tot }}^{+}$and $T_{\text {tot }}^{-}$, respectively. These sensitivity experiments therefore allow us to investigate the impact of diurnal variations in wind stress on the daily mean SST at day 0 , independently of the effects of diurnal variations in nonsolar heat flux. The time series of SST during day -1 and day 0 are shown in Fig. 14c, and the temperature profiles at the beginning of day 0 are shown in Fig. $14 \mathrm{~d}$ in gray and black for $T_{\tau}^{+}$and $T_{\tau}^{-}$, respectively.

At day 0 , we obtain a daily mean SST higher in $T_{\tau}^{+}$ than in $T_{\tau}^{-}$, by $0.17^{\circ} \mathrm{C}$, that is, $84 \%$ of the difference 
between $T_{\text {tot }}^{+}$and $T_{\text {tot }}^{-}$. The diurnal variations in wind stress therefore explain the main part of the difference between $T_{\text {tot }}^{+}$and $T_{\text {tot }}^{-}$. Furthermore, the effects of diurnal variations in wind stress and nonsolar heat flux are not additive. Their individual impacts amount to $0.17^{\circ}$ and $0.07^{\circ} \mathrm{C}$ while the total difference is $0.21^{\circ} \mathrm{C}$. At day -1 , the daily mean SST is higher by $0.03^{\circ} \mathrm{C}$ in $T_{\tau}^{-}$than in $T_{\tau}^{+}$. This is linked to the weaker wind stress in $T_{\tau}^{-}$than in $T_{\tau}^{+}$ during the diurnal warming, which allows for a larger peak in SST and thus a higher daily mean SST. Furthermore, the wind stress is larger (weaker) during the first (second) half of day -1 in $T_{\tau}^{+}$, that is, when the mixed layer is deeper (shallower). A large wind stress is more efficient in deepening a shallow than a deep mixed layer. This explains the more stable profile in $T_{\tau}^{+}$than in $T_{\tau}^{-}$at the beginning of day 0 . As in $T_{Q}^{+}$versus $T_{Q}^{-}$, the preconditioning of a shallower mixed layer allows more heat to be trapped near the surface during day 0 in $T_{\tau}^{+}$than in $T_{\tau}^{-}$. Another set of two experiments has been run in which the wind stress at day 0 was set to be constant and equal to their respective daily mean values in $T_{\tau}^{+}$and $T_{\tau}^{-}$, the other parameters being kept as in $T_{\tau}^{+}$and $T_{\tau}^{-}$, respectively. The temperature profiles at the beginning of day 0 were similar to those shown in Fig. 14d, but the differences in daily mean temperature between the two experiments were lower at day 0 than those shown in Fig. 14c. Thus, the impact of the diurnal variations in wind stress on the preconditioning of the mixed layer depth is not the only factor explaining the differences in daily mean temperature between $T_{\tau}^{+}$and $T_{\tau}^{-}$experiments. The strength of the wind stress during the peak of temperature at day 0 also plays a role. A weak wind stress, as in the $T_{\tau}^{+}$experiment, prevents heat from mixing downward and allows for a larger diurnal warming and a higher daily mean SST at day 0 than in the $T_{\tau}^{-}$experiment.

Additional sets of experiments were run by changing the amplitude of the diurnal variations in wind stress around their daily mean value. The stronger the anomalies in diurnal variations, the higher the difference in daily mean SST at day 0 between $T_{\tau}^{+}$and $T_{\tau}^{-}$experiments are, up to a critical value: when the wind stress reaches values of about $0.15 \mathrm{~N} \mathrm{~m}^{-2}$ whenever the time of this peak is during the day, this causes a deepening and cooling of the mixed layer during day -1 , which recovers only a few days after.

\section{Discussion}

\section{a. Amplitude of the signal}

To perform the sensitivity experiments presented in section 4 , we have used realistic time series of surface forcings that had been detected to favor a correction in daily mean SST by our composite analysis presented in section 3. The surface forcings applied in the $T_{\text {tot }}^{+}$and $T_{\text {tot }}^{-}$ experiments correspond to average composite diurnal variations in wind stress and nonsolar heat flux leading to a positive and a negative correction in daily mean SST, respectively. We obtain a difference in daily mean SST of $0.21^{\circ} \mathrm{C}$ at day 0 . Thus, we can estimate that taking into account diurnal variations in surface forcings such as those shown in gray in Fig. B1 would lead to a correction of the daily mean SST of about $0.1^{\circ} \mathrm{C}$, assuming a linear response, compared to a case for which daily mean forcings would be applied. In section 3, we have shown that the differences in daily mean surface temperature between ERA1h and ERA24h are on the order of $0.4^{\circ} \mathrm{C}$. These idealized experiments therefore only produce differences that amount to a quarter of the correction that can be attributed to the ocean diurnal variations. Three reasons can explain this discrepancy.

- In our idealized experiments, the daily mean mixed layer depth is about $10 \mathrm{~m}$, which corresponds to a mean value during the summer season (see Fig. 3). A shallower (deeper) mixed layer depth would lead to a higher (lower) correction in daily mean SST. The largest corrections in daily mean SST correspond to the period of shallowest mixed layer depth (Fig. 7).

- The compositing technique allows extraction of average diurnal variations that occurs together with a correction in daily mean SST. A variety of other diurnal variations in surface forcings could also lead to a correction in daily mean SST but less frequently. The diurnal variations in wind stress and nonsolar heat flux we extracted may only constitute the example of diurnal variations that lead the most frequently to such a correction in daily mean SST. Other factors that were not captured by this study may be involved to explain this correction.

- In section 3, we concluded from Fig. 8 that the correction in daily mean SST due to ocean diurnal variations has a mean persistence ranging from about 15 to 40 days in the midlatitudes (Fig. 8). This persistence can be mediated by an atmosphere-side persistence. If the atmospheric forcing persists in a way that tends to enhance the SST correction, the correction can grow during the episode up to an amplitude of about $0.4^{\circ} \mathrm{C}$. However, the diurnal variations in wind stress and non solar heat flux we extracted from composites do not allow us to explain such a persistence in the SST correction. Some other factors may be involved in this persistence.

\section{b. Differences between the tropics and the midlatitudes}

Two different mechanisms dominate in explaining the impact of the ocean diurnal cycle in the midlatitudes and in the tropics. Two reasons can explain these different behaviors: 
- Because of the distribution of the solar heat flux on the earth's surface, the equilibrium ocean mean state corresponds to a more stable mean profile below the mixed layer in the tropics than in the midlatitudes. This can favor a persistence of the nocturnal mixed layer depth in the tropics and explain why Shinoda (2005) found that the turbulent mixing during the night completely clears the mixed layer memory of the day. This result forms the base of Bernie et al. (2005) and Shinoda (2005) rectification mechanism explaining that a large diurnal warming is associated with a positive daily mean SST correction and hence taking into account that the ocean diurnal cycle leads to an increase in the amplitude of the intraseasonal SST variability. In contrast, our idealized experiments show a memory of the ocean column from one day to the following in the midlatitudes.

- Gentemann et al. (2008) found that extreme diurnal warmings were more frequent in the midlatitudes than in the tropics because of more frequent light wind events. This difference in surface wind characteristics may explain the dominant role of strong relative diurnal variations in wind speed (and thus in nonsolar heat flux and wind stress) on the daily mean SST correction in the midlatitudes while the role of daily peak in solar heat flux is dominant in the tropics.

\section{c. Nonresolved processes}

As the ocean model we used is a one-dimensional ocean model, heat and salt flux corrections were applied to account for advective and horizontal diffusive processes that are not explicitly resolved. The computation of these flux corrections was designed to force the mean state in ERA1h and ERA24h to be the same. The heat and freshwater corrections we applied are climatologies of temperature and salt trends. Thus, we do not expect an impact of these corrections on the diurnal to intraseasonal SST variability and on the results presented in this article as there is no variability on these time scales in these corrections.

Furthermore, our simulations did not take into account the diurnal variability of advective processes in the ocean. The combination of strong currents (e.g., western boundary currents, eddies) with high spatial SST variability could lead to an impact of the advection on the diurnal cycle of SSTs. Tanahashi et al. (2003) noted such cases in some confined areas such as in the Tasman Sea $\left(40^{\circ} \mathrm{S}, 160^{\circ} \mathrm{E}\right)$ or in the East Australian Current. However, Stuart-Menteth et al. (2003) considered that regions of high spatial SST gradients do not correspond to regions where the diurnal warming exceeds $0.5^{\circ} \mathrm{C}$. Thus, the role of ocean advective processes in the ocean diurnal variations seems to be negligible, but this impact remains to be assessed with an ocean general circulation model. By using such an ocean general circulation model, Bernie et al. (2007) showed that the rectification mechanism suggested by Bernie et al. (2005) to explain the role of the diurnal SST variability on the intraseasonal SST variability in the tropics was not affected by the representation of the advective processes. Some complementary experiments with an ocean general circulation model would be required to extend this conclusion to the midlatitudes.

Besides, the geostrophic currents are not reproduced by CNRMOM1D. The shearing of geostrophic currents could affect the turbulent kinetic energy profile and the processes by which the ocean diurnal variations act on the intraseasonal SST and surface heat fluxes variability. This aspect remains to be assessed with an ocean general circulation model to obtain an overall understanding of the role of the ocean diurnal variations on the oceanatmosphere interactions.

\section{d. Modeling setup}

The analyses presented in this paper are based on oceanforced simulations. We used the ECUME bulk formulae to compute turbulent surface fluxes (latent and sensible heat fluxes and wind stress), and the upwelling longwave radiative fluxes were computed in CNRMOM1D as a function of the SST. Thus, we partly account for the atmosphere sensitivity to SST. Nonetheless, a forced model offers a restricted view of the climate system. The interaction with the atmospheric component could alter the interaction between the diurnal and intraseasonal SST variability. To state this hypothesis, a complementary study in an atmosphere-ocean coupled mode would be necessary.

\section{Conclusions}

This study focuses on the role of the ocean diurnal variability on the SST variability on longer time scales. CNRMOM1D coupled with the GELATO3 sea ice model is forced by ERA-40 in the Atlantic Ocean with a forcing time step of one day in one simulation and with a time step of $6 \mathrm{~h}$ in the other $(1 \mathrm{~h}$ for the solar heat flux). This ocean model has 124 vertical levels with a vertical resolution of $1 \mathrm{~m}$ near the surface. The comparison between both experiments shows that the diurnal variations in the surface forcing fluxes affect the SST variability on seasonal and intraseasonal time scales. Sensitivity experiments with idealized forcings applied to an ocean column using CNRMOM1D are run to investigate the nonlinear physical processes responsible for the impact of the ocean diurnal variations on the intraseasonal SST variability in the midlatitudes.

The correction in daily mean SST when resolving the ocean diurnal variations can reach about $0.3^{\circ}-0.5^{\circ} \mathrm{C}$ while 
daily anomalies in SST typically reaches about $1^{\circ} \mathrm{C}$. Since such a temperature anomaly associated with the ocean diurnal variations persists on average for 15-40 days in the midlatitudes and more than 60 days in the tropics, the ocean diurnal variations are shown to affect the intraseasonal SST variability. In turn, the ocean diurnal variability may affect the ocean-atmosphere interactions on intraseasonal time scales.

Bernie et al. (2005) and Shinoda (2005) had already shown that taking into account the ocean diurnal cycle enhanced the intraseasonal SST variability by about $20 \%$ in the tropics because a positive correction in daily mean SST systematically occurs together with a positive anomaly in SST relative to the its seasonal mean. Our results are consistent with their so-called rectification mechanism in the tropics. In the midlatitudes, the diurnal variations in wind stress or nonsolar heat flux are shown to play a major role in the correction in daily mean SST. For example, a wind stress or nonsolar heat flux toward the atmosphere weaker during the second half of a day than during its first half preconditions a shallow mixed layer. The following day, as heat is trapped near the surface, the daily mean surface temperature is higher than if diurnal variations in wind stress or nonsolar heat flux toward the atmosphere were not resolved. We have performed sensitivity experiments in which an ocean column represented by CNRMOM1D is forced with these typical diurnal variations in wind stress and nonsolar heat flux. With these experiments, we show that this mechanism can explain roughly a quarter of the total daily mean correction that can be attributed to the ocean diurnal variations. However, the correction in daily mean SST due to ocean diurnal variations has been shown to have a mean persistence of about 15-40 days in the midlatitudes. This persistence could be mediated by an atmosphere-side persistence. If the atmospheric forcing persists in a way that enhances the SST correction, the correction could grow during the episode up to an amplitude of about $0.4^{\circ} \mathrm{C}$. A second mechanism, which was not captured by this study, may also be involved to explain this correction.

In this study, we focused on the mechanisms by which diurnal variations in wind stress or nonsolar heat flux can cause a correction in daily mean SST, but we did not attempt to explain the origin of these diurnal variations. To go further, we need to identify the weather types favoring these diurnal variations and how these situations can persist and favor the persistence of daily mean SST correction.

The CNRMOM1D-GELATO3 ocean-sea ice model will be coupled with an atmosphere general circulation model. This will allow us to assess the feedback of the diurnal SST variations on the diurnal atmosphere variations and how this feedback could alter the interactions between diurnal and intraseasonal SST variability. It will also enable us to investigate the impact of the diurnal oceanatmosphere coupling on the large-scale atmospheric circulation variability on intraseasonal time scales.

Acknowledgments. This work formed part of Virginie Guemas's Ph.D. Thesis at the Centre National de Recherches Météorologiques, Toulouse, funded by Météo-France and Commissariat à l'Energie Atomique (CEA). The authors wish to thank the three reviewers for their interesting suggestions, Pascal Terray and Eric Maisonnave for the availability of their statistical package STATPACK. This study was supported by the European Commission's 6th Framework Programme (ENSEMBLES, Contract GOCE-CT-2005-505539) and by the ANR Blanc CHAMPION.

\section{APPENDIX A}

\section{Wind Stress and Nonsolar Heat Flux Examples}

This appendix gathers a few examples of raw time series of wind stress and nonsolar heat flux selected from the first boreal summer of ERA1h simulation (year 1959) in the North Atlantic Ocean. These examples illustrate such sharp transitions in the forcings during the course of the day as those applied to CNRMOM1D in the idealized experiments in section 4 (Fig. 13). In Figs. A1a, A1b, and A1d, the wind stress decreases by $0.09-0.14 \mathrm{~N} \mathrm{~m}^{-2}$ in $12 \mathrm{~h}$ while the nonsolar heat flux increases by $50-80$ $\mathrm{W} \mathrm{m}{ }^{-2}$ in the meantime. Figure A1c illustrates simultaneous increase in wind stress by $0.12 \mathrm{~N} \mathrm{~m}^{-2}$ and decrease in nonsolar heat flux by $200 \mathrm{~W} \mathrm{~m}^{-2}$.

\section{APPENDIX B}

\section{Design of the Idealized Experiments}

In this appendix, we describe how the forcing fields for the two experiments $T_{\text {tot }}^{+}$and $T_{\text {tot }}^{-}$analyzed in section 4 were obtained and how the ocean initial conditions were selected. The solid and liquid precipitation are constant over time and set to $0 \mathrm{~mm}$ day $^{-1}$.

The surface turbulent fluxes are computed via the ECUME bulk formulae. The time series of the parameters needed to force the model - that is, $10-\mathrm{m}$ zonal and meridional wind speed, 2-m atmosphere temperature, 2-m specific humidity, and surface pressure are chosen to be as realistic as possible. Furthermore, for experiment $T_{\text {tot }}^{+}$, these parameters are chosen to follow a time series of diurnal variations in wind stress and nonsolar heat flux of the shape shown in Figs. 11 and 12, while for 
a) $46.1^{\circ} \mathrm{W}-45^{\circ} \mathrm{N}$ Solar peak $=1014 \mathrm{~W} \cdot \mathrm{m}^{-2}$

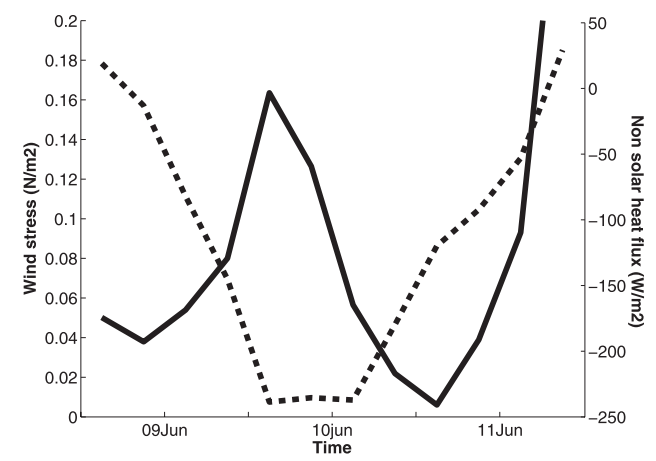

c) $61.9^{\circ} \mathrm{W}-39.4^{\circ} \mathrm{N}$ Solar peak $=882 \mathrm{~W} \cdot \mathrm{m}^{-2}$

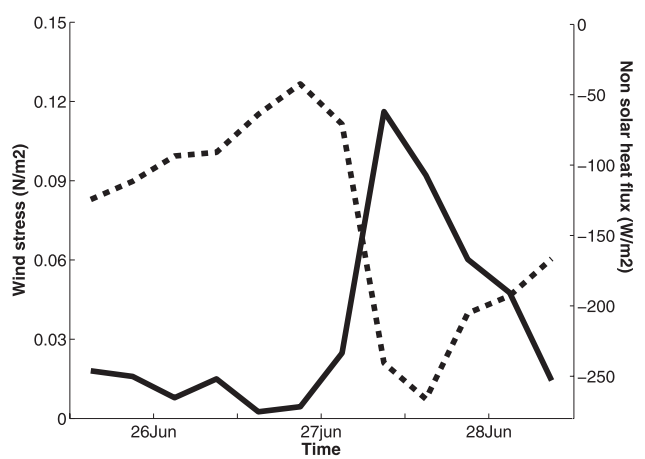

b) $11.2^{\circ} \mathrm{W}-42.8^{\circ} \mathrm{N}$ Solar peak $=843 \mathrm{~W} \cdot \mathrm{m}^{-2}$

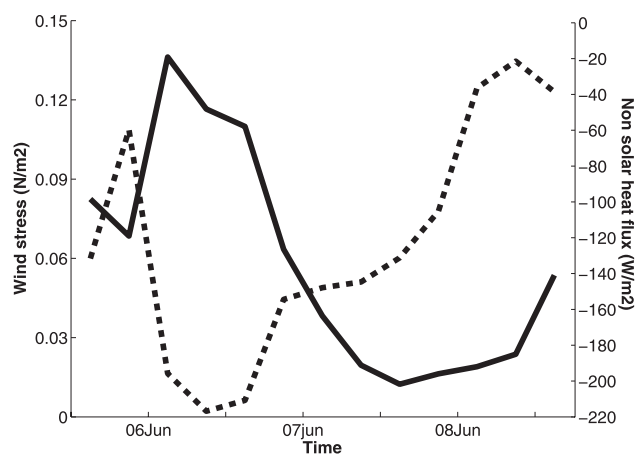

d) $28.1^{\circ} \mathrm{W}-55.1^{\circ} \mathrm{N}$ Solar peak $=628 \mathrm{~W} \cdot \mathrm{m}^{-2}$

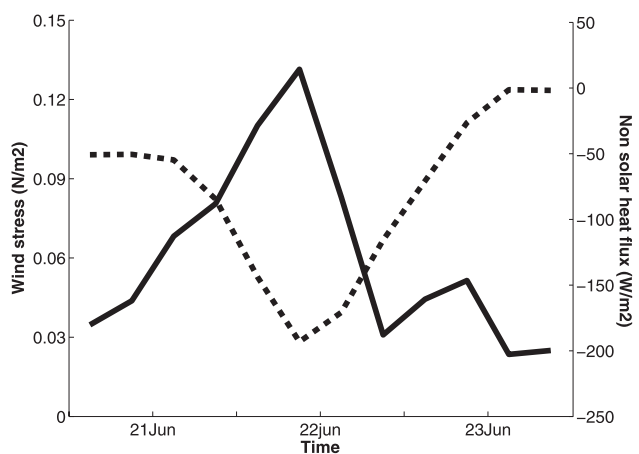

FIG. A1. Time series of wind stress (solid line), in $\mathrm{N} \mathrm{m}^{-2}$, and nonsolar heat flux (dashed line), in $\mathrm{W} \mathrm{m}^{-2}$ at various locations in the North Atlantic Ocean during the 1959 boreal summer of ERA1h simulation. The geographical locations are given in the title together with the peak in solar heat flux during the central day.

experiment $T_{\text {tot }}^{-}$, they are chosen to follow a time series of diurnal anomalies in wind stress and nonsolar heat flux relative to their daily mean with opposite signs. The time series of these parameters are shown in gray and black in Figs. B1a-c, for experiments $T_{\text {tot }}^{+}$and $T_{\text {tot }}^{-}$, respectively. The time series of meridional wind speed is the same as the time series of zonal wind speed. The surface pressure is constant over time and set to $1020 \mathrm{hPa}$. The upwelling longwave heat flux is computed using Stefan's (1879) law and the SST given by the model. The time series of downwelling longwave heat flux (Fig. B1d) are chosen to ensure that the sum of surface heat fluxes is the same in the $T_{\text {tot }}^{+}$and $T_{\text {tot }}^{-}$experiments and to give a time series of diurnal anomalies in nonsolar heat flux relative to their daily mean of the shape shown in Figs. 11 and 12 for experiment $T_{\text {tot }}^{+}$and of opposite signs for experiment $T_{\text {tot }}^{-}$. A positive heat flux corresponds to an input of heat in the ocean.

In all the sensitivity experiments, the solar heat flux varies according to an idealized diurnal cycle (Fig. 13a):

$$
\begin{cases}Q_{s}(t)=1000 \cos \left(\frac{t-12 \mathrm{~h}}{24 \mathrm{~h}} \pi\right) \mathrm{W} \mathrm{m}^{-2} & \text { if } \quad 6<x<18 \mathrm{~h} \\ Q_{s}(t)=0 \mathrm{~W} \mathrm{~m}^{-2} & \text { otherwise }\end{cases}
$$

where $t$ is local time.

Ocean initial conditions, that is, its temperature and salinity profiles, are computed as the area-average of an ocean restart of ERA1h for the 1 July over the mask shown in Fig. 11. We have tested that changing the year of the restart does not qualitatively affect our results.

\section{APPENDIX C}

\section{Quantifying the Impact of Preconditioning the Mixed Layer Depth}

Section 4 showed that the correction of the daily mean SST can be induced by several factors: 


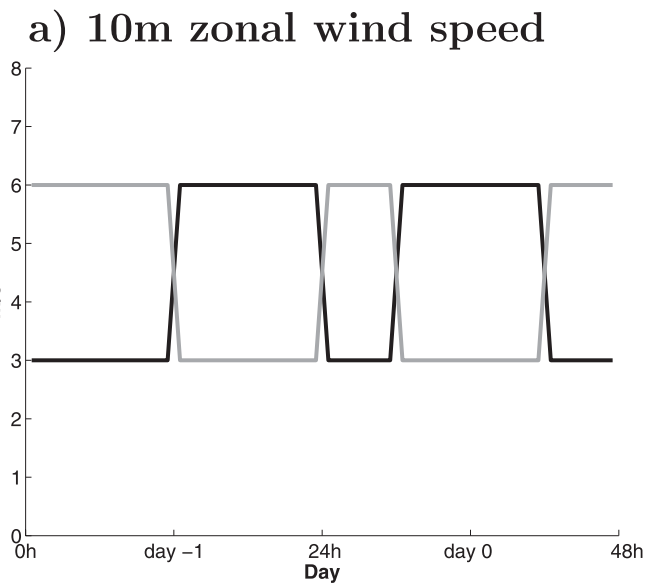

b) $2 \mathrm{~m}$ atmosphere temperature
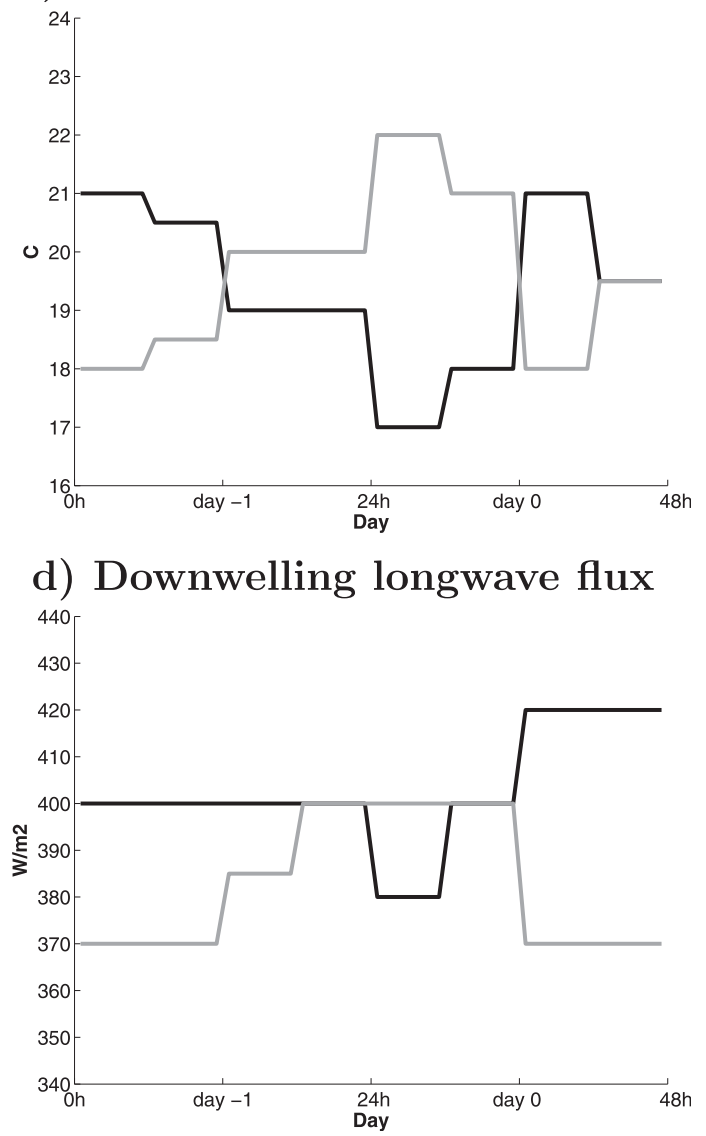

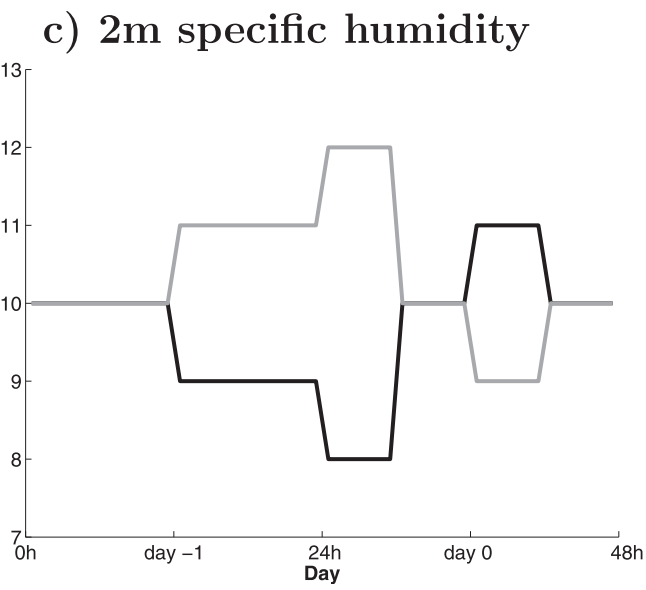

FIG. B1. Time series of the atmospheric data and surface fluxes applied in the idealized experiments $T_{\text {tot }}^{+}$(in gray) and $T_{\text {tot }}^{-}$(in black), described in section 4a: (a) 10-m zonal wind speed in $\mathrm{m} \mathrm{s}^{-1}$, (b) 2-m atmosphere temperature in ${ }^{\circ} \mathrm{C}$, (c) 2-m specific humidity in $\mathrm{g} \mathrm{kg}^{-1}$, and (d) downwelling longwave radiative flux in $\mathrm{W} \mathrm{m}^{-2}$.

- Since the net surface heat flux drives the SST trend, the evolution of the SST is delayed compared to the evolution of the nonsolar heat flux.

- A weak wind stress during the daily peak in SST prevents from mixing heat downward and allows for a large diurnal warming and a high daily mean SST.

- Diurnal variations in nonsolar heat flux during day -1 can precondition for a shallow mixed layer, by a weaker nonsolar heat flux toward the atmosphere during the second half of the day than during the first half, for example. The following day, as heat is trapped near the surface, the daily mean surface temperature is higher than if diurnal variations in nonsolar heat flux were not resolved.

- Similarly, diurnal variations in wind stress during day -1 can precondition for a shallow mixed layer, by a weaker wind stress during the second half of the day than during the first half, for example.

To quantify the effect of preconditioning the mixed layer depth by diurnal variations in wind stress and/or nonsolar heat flux, we perform a third set of complementary experiments consisting of $T_{\mathrm{MLD}}^{+}$and $T_{\mathrm{MLD}}^{-}$defined as follows. The time series of wind stress, nonsolar heat flux, and freshwater fluxes computed by CNRMOM1D during day -1 in the $T_{\text {tot }}^{+}$and $T_{\text {tot }}^{-}$experiments are used to force CNRMOM1D in the $T_{\mathrm{MLD}}^{+}$and $T_{\mathrm{MLD}}^{-}$, respectively. During day 0 , these forcings are kept constant at the value of the daily mean in $T_{\text {tot }}^{+}$and $T_{\text {tot }}^{-}$, respectively.

At day 0 , we obtain a higher daily mean SST in $T_{\mathrm{MLD}}^{+}$ than in $T_{\mathrm{MLD}}^{-}$, by $0.09^{\circ} \mathrm{C}$ (not shown), that is, about half of the difference between $T_{\text {tot }}^{+}$and $T_{\text {tot }}^{-}$at day 0 . Thus, the preconditioning of the mixed layer depth by diurnal variations in wind stress and nonsolar heat flux during day -1 is far from being negligible in explaining the changes in daily mean SST due to the representation of the ocean diurnal variations.

\section{REFERENCES}

Antonov, J. I., S. Levitus, T. P. Boyer, M. E. Conkright, T. D. O’Brien, and C. Stephens, 1998: Temperature of the Atlantic Ocean. Vol.1, World Ocean Atlas 1998, NOAA Atlas NESDIS 27, 166 pp. 
Belamari, S., 2005: Report on uncertainty estimates of an optimal bulk formulation for surface turbulent fluxes. Marine Environment and Security for the European Area-Integrated Project (MERSEA IP), Deliverable D4.1.2, 29 pp.

- and A. Pirani, 2007: Validation of the optimal heat and momentum fluxes using the ORCA2-LIM global ocean-ice model. Marine EnviRonment and Security for the European Area -Integrated Project (MERSEA IP). Deliverable D4.1.3, 88 pp.

Bellanger, H., 2007: Rôle de l'interaction océan-atmosphère dans la variabilité intrasaisonnière de la convection tropicale. Ph.D. thesis, Ecole Polytechnique, 203 pp.

Bernie, D. J., S. J. Woolnough, J. M. Slingo, and E. Guilyardi, 2005: Modeling diurnal and intraseasonal variability of the ocean mixed layer. J. Climate, 18, 1190-1202.

__ E. Guilyardi, G. Madec, J. M. Slingo, and S. J. Woolnough, 2007: Impact of resolving the diurnal cycle in an oceanatmosphere GCM. Part 1: A diurnally forced OGCM. Climate Dyn., 29, 575-590.

,,,,$---- \ldots$, and J. Cole, 2008: Impact of resolving the diurnal cycle in an ocean-atmosphere GCM. Part 2: A diurnally coupled CGCM. Climate Dyn., 31, 909-925.

Bjerknes, J., 1964: Atlantic air-sea interaction. Adv. Geophys., 10, $1-82$.

Bougeault, P., and P. Lacarrère, 1989: Parameterization of orographyinduced turbulence in mesobeta-scale model. Mon. Wea. Rev., 117, 1872-1890.

Briscoe, M. G., and R. A. Weller, 1984: Preliminary results from the Long Term Upper Ocean Study (LOTUS). Dyn. Atmos. Oceans, 8, 243-265.

Caniaux, G., A. Brut, D. Bourras, H. Giordani, A. Paci, L. Prieur, and G. Reverdin, 2005: A 1 year sea surface heat budget in the northeastern Atlantic basin during the POMME experiment: 1. Flux estimates. J. Geophys. Res., 110, C07S02, doi:10.1029/2004JC002596.

Cassou, C., C. Deser, L. Terray, J. W. Hurrel, and M. Drévillon, 2004a: Summer sea surface temperature conditions in the North Atlantic and their impact upon the atmospheric circulation in early winter. J. Climate, 17, 3349-3363.

_ L. Terray, J. W. Hurrell, and C. Deser, 2004b: North Atlantic winter climate regimes: Spatial asymmetry, stationarity with time, and oceanic forcing. J. Climate, 17, 1055-1068.

— C. Deser, and M. A. Alexander, 2007: Investigating the impact of reemerging sea surface temperature anomalies on the winter atmospheric circulation over the North Atlantic. J. Climate, 20, 3510-3526.

Chen, S. S., and R. A. Houze, 1997: Diurnal variation and life-cycle of deep convective systems over the tropical Pacific warm pool. Quart. J. Roy. Meteor. Soc., 123, 357-388.

Clayson, C. A., and A. Chen, 2002: Sensitivity of a coupled singlecolumn model in the Tropics to treatment of the interfacial parameterization. J. Climate, 15, 1805-1831.

Cornillon, P., and L. Stramma, 1985: The distribution of diurnal sea surface warming events in the western Sargasso Sea. J. Geophys. Res., 90, 11 811-11 815.

Czaja, A., and C. Frankignoul, 1999: Influence of the North Atlantic SST on the atmospheric circulation. Geophys. Res. Lett., 26, 2969-2972.

— , and —-, 2002: Observed impact of Atlantic SST anomalies on the North Atlantic Oscillation. J. Climate, 15, 606-623.

Dai, A., and K. E. Trenberth, 2004: The diurnal cycle and its depiction in the Community Climate System Model. J. Climate, 17, 930-951.

Danabasoglu, G., W. G. Large, J. J. Tribbia, P. R. Gent, B. P. Briegleb, and J. C. McWilliams, 2006: Diurnal coupling in the Tropical Oceans of CCSM3. J. Climate, 19, 2347-2365. de Boyer-Montégut, C. D., G. Madec, A. S. Fischer, A. Lazar, and D. Iudicone, 2004: Mixed layer depth over the global ocean: An examination of profile data and a profile based climatology. J. Geophys. Res., 109, C12003, doi:10.1029/2004JC002378.

Deschamps, P. Y., and R. Frouin, 1984: Large diurnal heating of the sea surface observed by the HCMR experiment. J. Phys. Oceanogr., 14, 177-184.

Drévillon, M., L. Terray, P. Rogel, and C. Cassou, 2001: Midlatitude Atlantic SST influence on European winter climate variability in the NCEP-NCAR Reanalysis. Climate Dyn., 18, 331-344.

, C. Cassou, and L. Terray, 2003: Model study of the wintertime atmospheric response to fall tropical Atlantic SST anomalies. Quart. J. Roy. Meteor. Soc., 129, 2591-2611.

Environmental Working Group, 1997a: Arctic climatology project. Russian Atlas of the Arctic Ocean-Winter Period, L. Timokhov and F. Tanis, Eds., Environmental Research Institute of Michigan, National Snow and Ice Data Center, CD-ROM.

_ 1997b: Arctic climatology project. Russian Atlas of the Arctic Ocean-Summer Period, L. Timokhov and F. Tanis, Eds., Environmental Research Institute of Michigan, National Snow and Ice Data Center, CD-ROM.

Fairall, C. W., E. F. Bradley, J. S. Godfrey, G. A. Wick, J. B. Edson, and G. S. Young, 1996: Cool-skin and warm-layer effects on sea surface temperature. J. Geophys. Res., 101, 12951308.

Flament, P., J. Firing, M. Sawyer, and C. Trefois, 1994: Amplitude and horizontal structure of a large diurnal sea surface warming event during the coastal ocean dynamics experiment. J. Phys. Oceanogr., 24, 124-139.

Gaspar, P., Y. Gregoris, and J. M. Lefevre, 1990: A simple eddy kinetic energy model for simulations of the oceanic vertical mixing: Tests at station Papa and long-term upper ocean study site. J. Geophys. Res., 95, 16 179-16 193.

Gentemann, C. L., P. J. Minett, P. L. Borgne, and C. J. Merchant, 2008: Multi-satellite measurements of large diurnal warming events. Geophys. Res. Lett., 35, L22602, doi:10.1029/ 2008GL035730.

Gibson, J. K., P. Kallberg, S. Uppala, A. Hernandez, A. Nomura, and E. Serrano, 1997: ERA description. ECMWF Reanalysis Project Tech. Rep. 1, 71 pp.

Giordani, H., G. Caniaux, and L. Prieur, 2005a: A simplified 3D oceanic model assimilating geostrophic currents: Application to the POMME experiment. J. Phys. Oceanogr., 35, 628-644.

,,$-- \ldots$, A. Paci, and S. Giraud, 2005b: A 1 year mesoscale simulation in the northeast Atlantic: Mixed layer heat and mass budgets during the POMME experiment. J. Geophys. Res., 110, C07S08, doi:10.1029/2004JC002765.

_ L. Lrieur, and G. Caniaux, 2006: Advanced insights into sources of vertical velocity in the ocean. Ocean Dyn., 56, 513-514.

Grodsky, S. A., J. A. Carton, and H. Liu, 2008: Comparison of bulk sea surface and mixed layer temperatures. J. Geophys. Res., 113, C10026, doi:10.1029/2008JC004871.

Guemas, V., D. Salas-Mélia, M. Kageyama, H. Giordani, A. Voldoire, and E. Sanchez-Gomez, 2009: Winter interactions between weather regimes and marine surface ocean in the North Atlantic European region. Geophys. Res. Lett., 36, L09816, doi:10.1029/2009GL037551.

between weather regimes and surface ocean in the North Atlantic region. Climate Dyn., 34, 527-546, doi:10.1007/s00382008-0491-6. 
Hurrell, J. W., Y. Kushnir, G. Ottersen, and M. Visbeck, 2003: An overview of the North Atlantic Oscillation. The North Atlantic Simulation: Climate Significance and Environmental Impacts, Geophys. Monogr., Vol. 34, Amer. Geophys. Union, $1-22$.

Jerlov, N. G., 1976: Marine Optics. Elsevier, 229 pp.

Kantha, L. H., and C. A. Clayson, 1994: An improved mixed layer model for geophysical applications. J. Geophys. Res., 99, $25235-25266$.

Kawai, Y., and A. Wada, 2007: Diurnal sea surface temperature variation and its impact on the atmosphere and ocean: A review. J. Oceanogr., 63, 721-744.

Kennedy, J. J., P. Brohan, and S. F. B. Tett, 2007: A global climatology of the diurnal variations in sea-surface temperature and implications for MSU temperature trends. Geophys. Res. Lett., 34, L05712, doi:10.1029/2006GL028920.

Large, W. G., J. C. McWilliams, and S. C. Doney, 1994: Ocean vertical mixing: A review and a model with a nonlocal boundary layer parameterization. Rev. Geophys., 32, 363-403.

Maykut, G. A., 1982: Large-scale heat exchange and ice production in the Central Arctic. J. Geophys. Res., 87, 7971-7984.

Merchant, C. J., M. J. Filipiak, P. LeBorgne, H. Roquet, E. Autret, J.-F. Piolle, and S. Lavender, 2008: Diurnal warm-layer events in the western Mediterranean and European shelf seas. Geophys. Res. Lett., 35, L04601, doi:10.1029/2007GL033071.

Ohlmann, J. C., 2003: Ocean radiant heating in climate models. J. Climate, 16, 1337-1351.

Paulson, C. A., and J. J. Simpson, 1977: Irradiance measurements in the upper ocean. J. Phys. Oceanogr., 7, 952-956.

Price, J. F., R. A. Weller, and R. Pinkel, 1986: Diurnal cycling: Observations and models of upper ocean response to diurnal heating, cooling, and wind mixing. J. Geophys. Res., 91, 84118427.

Ramos Buarque, S., H. Giordani, G. Caniaux, and S. Planton, 2004: Evaluation of ERA-40 air-sea surface heat flux spin-up. Dyn. Atmos. Oceans, 37, 295-311.

Rayner, N. A., D. E. Parker, E. B. Horton, C. K. Folland, L. V. Alexander, D. P. Rowell, E. C. Kent, and A. Kaplan, 2003: Global analyses of sea surface temperature, sea ice, and night marine air temperature since the late nineteenth century. J. Geophys. Res., 108, 4407, doi:10.1029/2002JD002670.

Reynolds, R. W., T. M. Smith, C. Liu, D. B. Chelton, K. S. Casey, and M. G. Schlax, 2007: Daily high-resolution blended analyses for sea surface temperature. J. Climate, 20, 5473-5496.

Roll, H. U., 1965: Physics of the Marine Atmosphere. International Geophysics Series, Vol. 7. Academic Press, 426 pp.

Salas-Mélia, D., 2002: A global coupled sea ice-ocean model. Ocean Modell., 4, 137-172.

Shinoda, T., 2005: Impact of the diurnal cycle of solar radiation on intraseasonal SST variability in the western equatorial Pacific. J. Climate, 18, 2628-2636.

, and H. H. Hendon, 1998: Mixed layer modeling of intraseasonal variability in the tropical western Pacific and Indian Oceans. J. Climate, 11, 2668-2685.
Simonsen, K., and P. M. Haugan, 1996: Heat budgets of the Arctic, Mediterranean and sea surface heat flux parameterizations for the Nordic Seas. J. Geophys. Res., 101, 6553-6576.

Soloviev, A., and R. Lukas, 1997: Observation of large diurnal warming events in the near-surface layer of the western equatorial warm pool. Deep-Sea Res. I, 44, 1055-1076.

— ture, Dynamics, and Application, Vol. 31. Springer, 572 pp.

Steele, M., R. Morley, and W. Ermold, 2001: PHC: A global ocean hydrography with a high quality Arctic Ocean. J. Climate, 14, 2079-2087.

Stefan, J., 1879: On the relationship between thermal radiation and temperature (in German). Bulletins from the Sessions of the Vienna Academy of Sciences, Bd 79, 391-428.

Stramma, L., P. Cornillon, R. A. Weller, J. F. Price, and M. G. Briscoe, 1986: Large diurnal sea surface temperature variability: Satellite and in situ measurements. J. Phys. Oceanogr., 16, 827-837.

Stuart-Menteth, A. C., I. S. Robinson, and P. G. Challenor, 2003: A global study of diurnal warming using satellite-derived sea surface temperature. J. Geophys. Res., 108, 3155, doi:10.1029/ 2002JC001534.

Sui, C. H., K. M. Lau, Y. N. Takayabu, and D. A. Short, 1997: Multiscale air-sea interactions during TOGA-COARE. Mon. Wea. Rev., 125, 448-462.

Sverdrup, H. U., M. W. Johnson, and R. H. Fleming, 1942: The Oceans: Their Physics, Chemistry, and General Biology. PrenticeHall, 1087 pp.

Tanahashi, S., H. Kawamura, T. Takahashi, and H. Yusa, 2003: Diurnal variations of sea surface temperature over the wide-ranging ocean using VISSR on board GMS. J. Geophys. Res., 108, 3216, doi:10.1029/2002JC001313.

Terray, L., and C. Cassou, 2002: Tropical Atlantic sea surface temperature forcing of quasi-decadal climate variability over the North Atlantic-European region. J. Climate, 15, 31703187.

Uppala, S., and Coauthors, 2004: ERA-40: ECMWF 45-year reanalysis of the global atmosphere and surface conditions 19572000. ECMWF Newsletter, No. 101, ECMWF, Reading, United Kingdom, 2-21.

Ward, B., 2006: Near-surface ocean temperature. J. Geophys. Res., 111, C02005, doi:10.1029/2004JC002689.

Webster, P. J., and R. Lukas, 1992: TOGA COARE: The Coupled Ocean-Atmosphere Response Experiment. Bull. Amer. Meteor. Soc., 73, 1377-1416.

Woolnough, S. J., J. M. Slingo, and B. J. Hoskins, 2000: The relationship between convection and sea surface temperature on intraseasonal timescales. J. Climate, 13, 2086-2104.

_ , F. Vitart, and M. A. Balmaseda, 2007: The role of the ocean in the Madden-Julian Oscillation: Implications for MJO prediction. Quart. J. Roy. Meteor. Soc., 133, 117-128.

Yokoyama, R., S. Tanba, and T. Souma, 1995: Sea surface effects on the sea surface temperature estimation by remote sensing. Int. J. Remote Sens., 16, 227-238. 